\title{
Influenza Virus RNA-Dependent RNA Polymerase and the Host Transcriptional Apparatus
}

Tim Krischuns ${ }^{1}$, Maria Lukarska ${ }^{2 *}$, Nadia Naffakh ${ }^{1}$ and Stephen Cusack ${ }^{2 \#}$

${ }^{1}$ Institut Pasteur, Unité Biologie des ARN et Virus Influenza, Département de Virologie, CNRS - UMR 3569, F-75015 Paris, France

${ }^{2}$ European Molecular Biology Laboratory, 71 Avenue des Martyrs, CS 90181, 38042 Grenoble Cedex 9, France

*Current address: Department of Molecular and Cell Biology, University of California, Berkeley, Berkeley, CA 94720, USA

\#Corresponding author: Stephen Cusack, European Molecular Biology Laboratory, Grenoble Outstation, Grenoble Cedex 9, France. Tel. (33)476207238, Email: cusack@embl.fr

Submitted to Annual Review of Biochemistry on the $28^{\text {th }}$ July 2020. 


\section{Contents}

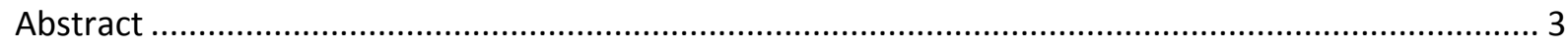

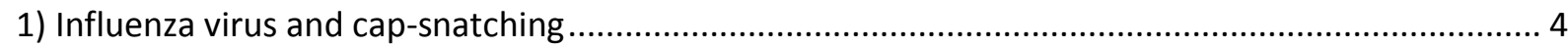

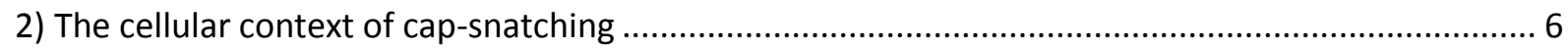

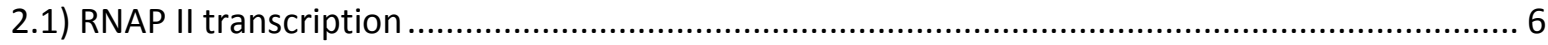

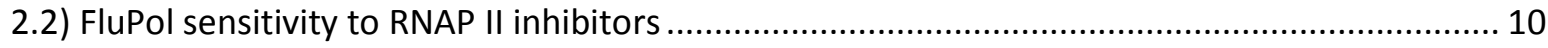

2.3) FluPol interactions with the host transcription machinery ...................................................... 11

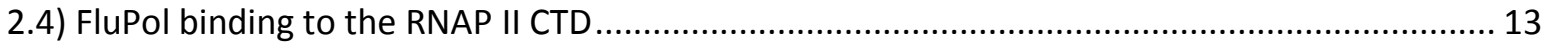

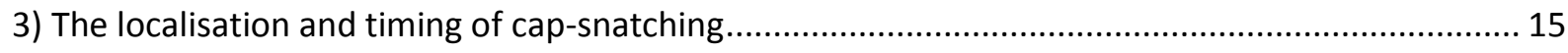

3.1) Intranuclear sites of RNAP II and FluPol transcription .......................................................... 15

3.2) FluPol access to nascent capped RNAP II transcripts............................................................ 17

3.3) FluPol cap preference and competition with the host CBC complex ..................................... 19

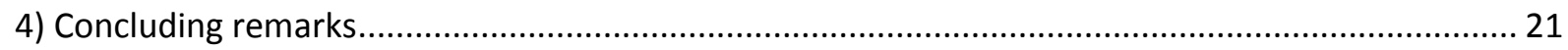

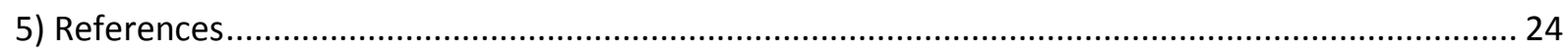

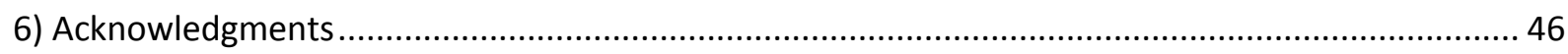

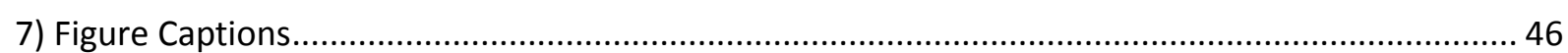

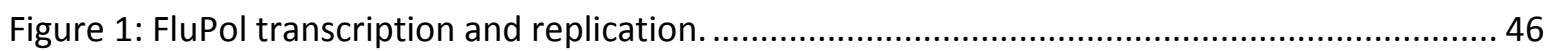

Figure 2: The initiation, pausing and pause release steps of early RNAP II transcription.................. 46

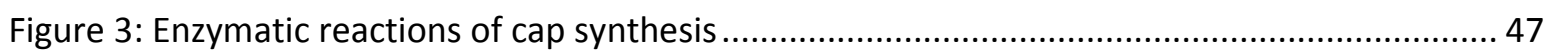

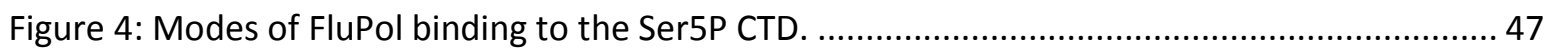

Figure 5: Open questions on FluPol cap-snatching: timing and context...................................... 48

Table 1. Influenza virus interplay with host factors involved in cellular mRNA biogenesis............. 49 


\begin{abstract}
Influenza virus RNA-dependent RNA polymerase (FluPol) transcribes the viral RNA genome in the infected cell nucleus. In the 1970s, viral transcription was shown to depend on host RNA polymerase II (RNAP II) activity, and, subsequently that FluPol 'snatches' cappedoligomers from nascent RNAP II transcripts to prime its own transcription. Exactly how this occurs remains elusive. Here we review recent advances in the mechanistic understanding of FluPol transcription and early events in RNAP II transcription that are relevant to capsnatching. We describe the known direct interactions between FluPol and RNAP II C-terminal domain (CTD) and summarise the transcription-related host factors that have been found to interact with FluPol. Finally, we discuss open questions as to how FluPol may be targeted to actively transcribing RNAP II and the exact context and timing of cap-snatching, which is presumed to occur after cap-completion but before the cap is sequestered by the nuclear capbinding complex.
\end{abstract}




\section{1) Influenza virus and cap-snatching}

Influenza is an acute infectious respiratory disease that is mainly caused by influenza viruses of the genera $\mathrm{A}$ and $\mathrm{B}$. While human infections with influenza A (IAV) and B (IBV) viruses cause annually recurring epidemics of seasonal influenza, which affect $10-30 \%$ of the global population and kill 290000 - 650000 people each year, influenza C viruses (ICV) usually cause milder respiratory syndromes. Occasionally, IAVs of animal origin cross the species barrier to humans causing "pandemic influenza", which can have devastating consequences in terms of mortality and economical loss and pose a perennial worldwide threat ${ }^{1}$. Understanding the mechanism of viral replication is key to improve prevention and treatment of influenza disease.

Influenza viruses have a segmented, single-stranded RNA genome of negative (-) polarity and unlike most RNA viruses, replicate in the nucleus of infected cells (Figure $1 \mathbf{A})^{2}$. Each of the eight genomic viral RNA (vRNA) segments is encapsidated by multiple copies of the viral nucleoprotein (NP) together with a single copy of the RNA-dependent RNA polymerase (FluPol). This complex is referred to as viral ribonucleoprotein complex (vRNP) and is the functional unit for transcription and replication ${ }^{3}$. After virus internalization, vRNPs are released into the cytosol and subsequently imported into the nucleus, where the first rounds of viral mRNA transcription occur (primary transcription) (Figure 1A). FluPol replicates the viral genome by copying vRNAs into intermediate positive-sense complementary RNAs (cRNAs), which in turn serve as templates for the synthesis of new vRNAs. The cRNAs and vRNAs are co-transcriptionally packaged with newly synthetized NP and FluPol to form progeny vRNPs and cRNPs. Progeny vRNPs serve as a template for further (secondary) transcription and replication (Figure 1A, dotted lines). At late stages of the infection cycle, viral transcription declines and vRNPs are exported from the nucleus to the host cell plasma membrane, where they are incorporated into new virions ${ }^{2}$. 
FluPol is a heterotrimer composed of the subunits PA (polymerase acidic protein), PB1 (polymerase basic protein 1) and PB2 (polymerase basic protein 2) ${ }^{4}$. X-ray crystallography and cryo-electron microscopy (cryo-EM) have revealed that FluPol is a highly dynamic molecule with many flexible-linked domains that can adopt multiple conformations corresponding to different functional states ${ }^{5-9}$. FluPol performs transcription and replication of the viral genome through very different processes. Whereas replication is initiated by a primer-independent mechanism ${ }^{10,11}$, transcription of viral mRNAs is primer-dependent ${ }^{9,12}$. Replication generates exact, full-length genome copies, while transcription results in mRNAs with a $5^{\prime}$ terminal $\mathrm{N}^{7}$-methylguanosine $\left(\mathrm{m}^{7} \mathrm{G}\right)$ cap and a $3^{\prime}$ poly $(\mathrm{A})$ tail ${ }^{9,13}$ that are competent for translation by the host translation machinery ${ }^{14}$.

In contrast to many other RNA viruses, FluPol does not possess any inherent capping activity $^{15}$. This initially puzzling observation was explained in the late 70 's by the Krug laboratory. They demonstrated that FluPol utilises short capped oligomers derived from capped host RNAs to prime transcription of viral mRNAs ${ }^{16,17}$. In a process referred to as "cap-snatching", the PB2 cap binding domain binds to the 5' cap of nascent host RNA polymerase II (RNAP II) transcripts ${ }^{18}$ and the PA endonuclease cleaves 10-15 nucleotides downstream of the cap to generate the primers that initiate transcription (Figure 1B, a) ${ }^{19,20}$. Polyadenylation is achieved by a non-canonical mechanism involving stuttering of the viral polymerase at a 5' proximal oligo(U) polyadenylation signal present on each genomic $\mathrm{vRNA}^{9,21}$. Recently, the initiation, elongation, polyadenylation and recycling states (Figure 1B, b-e) of the complete FluPol transcription cycle have been visualised by a combination of X-ray crystallography and cryo-EM ${ }^{4,9,22}$. It was shown that the $5^{\prime}$ and $3^{\prime}$ vRNA extremities always remain bound to the polymerase while moving along the vRNA, thereby allowing efficient recycling from the termination back to the initiation state of viral transcription (Figure 1B, d-e) $)^{9,23,24}$. 
The cap-snatching mechanism is common to all segmented, negative-sense RNA viruses $^{25}$. However, cap-snatching of orthomyxoviruses such as influenza uniquely occurs in the nucleus, whereas members of the large Bunyavirales order perform cap-snatching in the cytoplasm. It has long been known that influenza viral replication is dependent on active host RNAP II ${ }^{26,27}$. Moreover, it was shown that cap-snatching requires an intimate association with the RNAP II transcription machinery (Figure 1A-B) ${ }^{28,29}$. The RNA targets of FluPol cap-snatching, as well as the impact of an influenza infection on RNAP II transcription have been recently reviewed ${ }^{30}$. Here, we focus on the recent significant, often structure-based, advances in the mechanistic understanding of both FluPol and RNAP II transcription with the aim of trying to understand how the two processes are coupled. We review FluPol associated host factors and discuss possible steps of RNAP II transcription that could allow capsnatching by FluPol. Moreover, we discuss the recent concepts of compartmentalisation and phase separation of RNAP II and put them into the perspective of the cap-snatching process.

\section{2) The cellular context of cap-snatching}

\section{1) RNAP II transcription}

Eukaryotic cells encode three multi-subunit RNA polymerases, RNAP I-III ${ }^{31}$. RNAP II transcribes all protein-coding mRNAs and diverse non-coding RNAs, including long non-coding RNAs ${ }^{32}$, micro RNAs ${ }^{33}$, small nuclear RNAs (snRNAs) ${ }^{34}$ and small nucleolar RNAs (snoRNAs) ${ }^{35}$. RNAP II is composed of 12 subunits, of which the largest subunit RPB1, has a long unstructured C-terminal domain $(\mathrm{CTD})^{36}$. The CTD consists of three regions: a tip, a middle part of repetitive nature and a linker, which connects the CTD to the RPB1 core. The middle region consists of heptapeptide repeats with the consensus sequence Tyr-Ser-Pro-ThrSer-Pro-Ser $\left(\mathrm{Y}_{1} \mathrm{~S}_{2} \mathrm{P}_{3} \mathrm{~T}_{4} \mathrm{~S}_{5} \mathrm{P}_{6} \mathrm{~S}_{7}\right)$. While the heptad motif is conserved between species, the number of repeats and hence CTD length markedly differs between species, as illustrated by 
26 CTD repeats in $S$. cerevisiae and 52 repeats in mammals, respectively ${ }^{37}$. The CTD is subject to diverse post-translational modifications including phosphorylation, glycosylation, methylation, ubiquitination and acetylation ${ }^{36}$. The modification pattern of the CTD evolves in a regulated fashion during RNAP II transcription, thereby defining the 'CTD code', which is fundamental for the spatiotemporal control of transcription. The CTD directly binds or indirectly recruits co-transcription factors and thereby serves as a scaffold for diverse RNA processing factors and transcriptional regulators ${ }^{38}$.

RNAP II transcription is initiated by the recruitment of general transcription factors (GTFs) and RNAP II to the promoter region, thereby forming the pre-initiation complex (PIC) (Figure 2a) $^{39}$. A crucial regulator of transcriptional initiation is the Mediator complex, a large protein complex with variable subunit composition ${ }^{40}$, which stabilises the $\mathrm{PIC}^{41}$ and functionally couples the PIC with chromatin remodellers and transcriptional regulators ${ }^{42}$. The Mediator complex interacts with $\mathrm{GTFs}^{43}$ as well as the unphosphorylated RNAP II CTD ${ }^{44,45}$, facilitating CTD Ser5 and Ser7 phosphorylation by the TFIIH subunit cyclin-dependent kinase 7 (CDK7), which in turn leads to Mediator release and RNAP II promotor escape $(\text { Figure 2b) })^{46}$.

RNAP II pausing 20-100 base pairs downstream from the transcription start site is a decisive step for the control of transcriptional elongation ${ }^{47}$. RNAP II pausing rates are highly regulated and contribute to gene-specific transcriptional outputs ${ }^{48-50}$. RNAP II pausing is dependent on DNA sequence elements in the promotor proximal region ${ }^{51}$, as well as on specific negative elongation factors, which provoke tilting of the DNA-RNA hybrid in the active site cavity of the paused RNAP II complex, thus preventing RNA chain elongation ${ }^{52,53}$. Paused RNAP II is stabilized by 5,6-Dichloro-1-beta-D-ribofuranosylbenzimidazole (DRB) sensitivity-inducing factor (DSIF), a dimeric complex formed by SPT4 and SPT5 ${ }^{54}$, and the negative elongation factor (NELF), a heterotetramer formed by subunits NELF-A, B, C or D, E (Figure $2 \mathbf{b}-\mathbf{c})^{55,56}$. SPT5 comprises multiple subdomains, which extensively interact with the RNAP II surface, 
the DNA template, as well as the exiting $\mathrm{RNA}^{52,53,57}$. The C-terminal region (CTR) of human SPT5 consists of pentapeptide repeats with the consensus sequence Gly-Ser-Gln/Arg-Thr-Pro, with the Ser and Thr residues undergoing phosphorylation (Figure $2 \mathbf{d})^{58}$. Similar to the RNAP II CTD repeats, the SPT5 CTR plays a role in the recruitment of transcriptionassociated factors $^{59}$. NELF also makes multiple interactions with RNAP II, restricting its mobility and preventing the binding of TFIIS ${ }^{60}$, a factor that aids re-alignment of the DNARNA hybrid and restart of elongation after transient pausing or transcriptional arrest ${ }^{53,61}$.

Capping of nascent RNAP II transcripts occurs immediately after emergence of the RNA 5' end triphosphate from the RNA exit tunnel and is tightly coupled to RNAP II pausing (Figure 2b) ${ }^{62-64}$. Capping is crucial for transcript stability, subsequent processing, intranuclear transport, nuclear export and, in the case of mRNA, translation ${ }^{65}$. Shortly after cap completion, the modified 5' end of the nascent RNA is bound by the nuclear cap-binding complex (CBC) (Figure 2d). The heterodimeric CBC consists of the nuclear cap-binding protein $1 / 2(\mathrm{NCBP} 1 / 2)^{66,67}$ and interacts with several RNA processing complexes, including those for splicing ${ }^{68}$, U snRNA-export ${ }^{69}$, RNA degradation ${ }^{70}$ and $3^{\prime}$ end processing ${ }^{71}$, thereby playing a fundamental role in mediating the function of the 5' cap structure.

The $5^{\prime}$ cap structure is characterised by an $\mathrm{N}^{7}$-methylguanosine linked via an inverted $5^{\prime}-5^{\prime}$ triphosphate bridge to the 5'-terminal nucleoside of the transcript and its synthesis requires a series of enzymes (Figure 3$)^{72}$. The formation of the minimal cap 0 structure is catalysed by three enzymes, namely RNA-5'-triphosphatase (RT), guanylyltransferase (GT) and RNA guanine- $\mathrm{N}^{7}$-methyltransferase (RNMT) (Figure 3a-c) ${ }^{65,73}$. In mammals, $\gamma$ phosphate hydrolysis and guanylyl transfer are catalysed by the capping enzyme $(\mathrm{CE})^{74,75}$. The guanosine capped structure is a substrate for a series of further methylations. RNMT transfers a methyl group to the $\mathrm{N}^{7}$ of the guanosine to form the cap 0 structure ${ }^{76}$, which is crucial for CBC binding and efficient translation of mRNA (Figure $3 \mathbf{c})^{77}$. The cap 0 structure normally undergoes further methylation of the 2'-OH on the ribose of the first nucleotide, 
catalysed in higher eukaryotes by the cap-specific mRNA methyltransferase $1(\text { CMTR } 1)^{78}$, thereby generating the cap 1 structure (Figure 3d). The cap 1 structure is a hallmark of bone fide cellular RNAs, whereas cap 0 is recognised as non-self by innate immune receptors such as RIG-I ${ }^{79,80}$. The $2^{\prime}$-O-ribose of the second nucleotide can be methylated by CMTR2 ${ }^{81}$, resulting in the cap 2 structure (Figure 3e), which is only present in about half of capped mRNAs $^{82}$ and is suggested to increase RNA stability ${ }^{83}$. Moreover, it was recently demonstrated that the majority of mRNAs that start with an A are methylated at the $\mathrm{N}^{6} \mathrm{~A}$ position by the cap-specific adenosine methyltransferase (CAPAM) (Figure 3f $)^{84}$.

The recruitment of the CE to paused RNAP II and its allosteric activation is mediated by a direct interaction with the Ser5P RNAP II CTD ${ }^{85-88}$, with additional interactions being made to DSIF, particularly the SPT5-CTR ${ }^{89,90}$. CTD-independent interactions with RNAP II position the $\mathrm{CE}$ in proximity to the emerging transcript at the RNA exit tunnel, further enhancing CE activity ${ }^{74,91}$. The methyltransferases CMTR $1^{92}$ and $\mathrm{CAPAM}^{84}$ also bind to the Ser5P CTD, illustrating the crucial role of CTD Ser5P in the co-transcriptional capping of nascent RNAP II transcripts.

The kinase activity of the positive transcription elongation factor $b(\mathrm{P}-\mathrm{TEFb})$ essentially regulates RNAP II pause release ${ }^{93}$. P-TEFb consists of CDK9 in complex with cyclin $\mathrm{T} 1 / 2^{94}$ (Figure 2d). Before its activation, $\mathrm{P}-\mathrm{TEFb}$ is sequestered by the $7 \mathrm{SK}$ snRNP (small nuclear ribonucleoprotein) complex in an inactive state ${ }^{95}$. P-TEFb activation and recruitment to promotor proximal regions is tightly regulated and several different mechanisms of activation have been proposed $^{93}$. These include the concerted actions of $\mathrm{Brd} 44^{96}$ and the protein phosphatases PP2B and PP1 $1 \alpha^{97,98}$, as well as the recruitment of P-TEFb to promotor-proximal regions by TRIM $28^{99}$. Upon activation and recruitment to paused RNAP II, CDK9 phosphorylates the CTR of SPT5 ${ }^{58}, \mathrm{NELF}^{100}$, the positive elongation factor PAF1 complex (PAF) and Ser2 of RNAP II CTD ${ }^{101}$, which triggers the formation of an activated RNAP II elongation complex ${ }^{102}$. DSIF phosphorylation is critical for transcriptional 
elongation and converts DSIF into a positive elongation factor ${ }^{58}$. PAF1 binding competes with NELF, leading to the exclusion of NELF from the elongating RNAP II complex ${ }^{53,102}$. CDK9 phosphorylation of the CTD linker region enables the binding of the elongation factor SPT $6^{102}$. Overall, the activity of P-TEFb leads to RNAP II release from the pausing state and transition into productive elongation ${ }^{103}$.

\section{2) FluPol sensitivity to RNAP II inhibitors}

Early investigations into the effect of RNAP II inhibitors on influenza virus multiplication such as $\alpha$-amanitin and actinomycin D, first established that FluPol transcription requires active RNAP II transcription. $\alpha$-amanitin traps an RNAP II translocation intermediate $^{104}$, thereby inhibiting nucleotide incorporation and blocking both RNAP II initiation and elongation. Actinomycin D is a DNA intercalating agent that generally interferes with DNA-templated RNA synthesis ${ }^{105}$. In contrast to other RNA viruses, which replicate in the cytoplasm ${ }^{27,106}$, actinomycin D and $\alpha$-amanitin efficiently inhibit influenza virus multiplication when added early in infection ${ }^{27,107-109}$. Inhibition by $\alpha$-amanitin is specifically related to RNAP II activity, as the virus is insensitive to the drug in cells that express an $\alpha$-amanitin-resistant RNAP II ${ }^{26,110,111}$. Treatment with $\alpha$-amanitin or actinomycin D prevents the accumulation of all three types of viral RNAs (vRNAs, cRNAs and mRNAs). However, there is ample evidence that only viral transcription is directly dependent on RNAP II activity. If FluPol and viral nucleoprotein are expressed prior to $\alpha$-amanitin or actinomycin D treatment and infection, vRNAs and cRNAs still accumulate while mRNA transcription is strongly impaired ${ }^{26,112}$, thereby demonstrating the drugs specific effect on viral transcription. The effect of $\alpha$-amanitin or actinomycin D on viral replication is indirect, as replication is strictly dependent on viral protein expression and hence on viral $\operatorname{transcription}^{26,110,113}$. 
Influenza virus growth was also reduced in the presence of CDK9 kinase inhibitors, such as DRB ${ }^{114}$ and flavopiridol ${ }^{115}$. However, DRB and flavopiridol also inhibit to a lesser extent other kinases (e.g. CDK7 for DRB, CDK1, CDK2, CDK4, CDK8 for flavopiridol ${ }^{116}$ ), complicating the interpretation of the observed effects. Both compounds prevent RNAP II hyperphosphorylation and elongation ${ }^{117-119}$. DRB is reported not to inhibit transcription of viral mRNAs and its effect on influenza virus multiplication is at least partly explained by inhibition of viral mRNA export ${ }^{26,120}$. This, taken together with the fact that FluPol preferentially associates with the Ser5P CTD of RNAP II (Section 2.4) ${ }^{28}$, suggests that RNAP II activity prior to hyperphosphorylation by $\mathrm{P}-\mathrm{TEFb}$ is sufficient for FluPol capsnatching.

\section{3) FluPol interactions with the host transcription machinery}

Several observations suggest that multiple interactions of FluPol with the host transcriptional machinery are required to allow efficient cap-snatching. FluPol directly interacts with the RNAP II $\mathrm{CTD}^{28}$ and this interaction was shown to be essential for viral transcription (Section 2.4) ${ }^{29}$. Moreover, intranuclear dynamics of vRNPs suggest that the association of FluPol with RNAP II is established by multiple interactions ${ }^{121}$. Indirect interactions with RNAP II through other transcription associated factors could be involved. In recent years, several proteomic studies and genome-wide loss of function screens using CRISPR-Cas9 knockouts or siRNA-mediated knockdown have documented IAV-host protein interactions. There is little overlap between the hit lists of the different screens ${ }^{122,123}$, which is likely due to differences in the experimental setting and selection criteria for the hits. A limitation of loss of function screens is the toxicity that might result from the depletion of essential host proteins. Nevertheless, these high-throughput approaches provide extensive data on physical and functional connections between influenza proteins and host transcriptionrelated factors ${ }^{122-125}$. Hits that were found in at least two independent screens and which are 
potentially relevant with respect to the RNAP II context of cap-snatching are listed in Table 1. Few have been validated and their precise role during influenza infection remains poorly characterised.

Interestingly, few of the identified host factors correspond to the basal transcription initiation machinery or the Mediator complex (Table 1), suggesting that host factors associated with these steps of RNAP II transcription are not involved in the recruitment of FluPol. In contrast, several factors involved in the control of RNAP II pausing and elongation have been identified. Independent proteomic studies report an interaction of FluPol with the DSIF subunits SPT4 and SPT5 ${ }^{124-126}$ and one validated this interaction by coimmunoprecipitation experiments ${ }^{124}$. Other factors known to regulate or cooperate with SPT5 ${ }^{102,127,128}$ were found to interact with FluPol: the arginine methyltransferase PRMT5 ${ }^{124}$, the transcription elongation factors SPT6 ${ }^{125}$, PAF1 and Tat-SF1 ${ }^{124}$. PARP1, which ADPribosylates NELF and promotes transcriptional elongation ${ }^{129,130}$ and CDK9, a component of the $\mathrm{P}-\mathrm{TEFb}$ kinase responsible for pause release into productive elongation ${ }^{131}$ were also identified. Moreover, TRIM28, a negative factor of transcriptional elongation ${ }^{132}$ and CDK9 activity $^{133}$ was identified as a FluPol interaction partner ${ }^{126}$. However, functional and mechanistic data regarding the potential role of the described factors in influenza infection is scarce and sometimes contradictory. A positive effect of TRIM28 on influenza replication was reported by independent investigations ${ }^{134-137}$, which was assigned to a negative regulatory role of TRIM28 on the innate immune response ${ }^{136,138}$. However, TRIM28 is also reported to inhibit FluPol activity ${ }^{139}$, suggesting a multifunctional role during IAV infection. Two independent RNAi screens have pointed to a role of SPT6 in the viral life cycle ${ }^{140,141}$. PARP $1^{142,143}$ and P-TEFb ${ }^{131,139}$, when overexpressed or depleted, were found to affect FluPol activity. Moreover, Tat-SF1 was shown to positively regulate polymerase activity ${ }^{139}$ and stimulate viral replication by possibly playing a role in vRNP assembly, even though this was suggested to happen through interaction with NP rather than the polymerase ${ }^{144}$. 
Screening hits relevant to capping include the nuclear cap-binding subunits $\mathrm{NCBP} 1^{125,137}, \mathrm{NCBP} 2^{122,137}$ and $\mathrm{NCBP} 3^{137,145}$, as well as the methyltransferase CMTR1 (Figure 3d $)^{122}$. Downstream functional analyses confirmed a positive effect of CMTR1 on viral replication ${ }^{122}$. However, it remains unclear whether it is direct interactions between CMTR1 and FluPol or simply the cap modifying activity of CMTR1 that is important for viral replication.

Other nuclear proteins interacting with FluPol and/or potentially regulating FluPol activity include chromatin-associated proteins and mRNA processing factors (Table 1). Only a few have been investigated in detail. Although the multifunctional DDB1 protein was identified as a hit in five independent proteomic studies or genetic screens ${ }^{125,126,129,130,146}$ and was shown to mediate PB2 ubiquitination ${ }^{147}$, its precise role in the viral life cycle has not been uncovered. Two chromatin-remodelling proteins, CHD6 and CHD1, were shown to interact with FluPol in infected cells and to act as a negative and positive regulator of FluPol activity, respectively ${ }^{148,149}$. A physical association between FluPol and the nuclear RNA exosome complex was also proposed to contribute to chromatin targeting of the viral polymerase to promoters, thereby promoting cap-snatching ${ }^{150}$. Many transcription factors are multifunctional and are involved in various steps of cellular RNA biosynthesis. However, to our knowledge there is no evidence that any of the RNA processing factors listed in Table 1 are directly involved in the influenza cap-snatching process.

\section{4) FluPol binding to the RNAP II CTD}

Biochemical and structural evidence demonstrate a physical association between FluPol and the RNAP II CTD. Co-immunoprecipitations show that FluPol specifically binds to CTD repeats when transiently expressed in the absence of other viral proteins and vRNA ${ }^{28}$, as well as in the context of vRNPs in infected cells ${ }^{151,152}$. Moreover, CTD binding enhances 
the in vitro transcriptional activity of FluPol, suggesting that CTD binding stabilises FluPol in a transcription-active conformation ${ }^{30,153}$.

Biophysical and structural investigations, using synthetic peptides corresponding to a few heptad repeats of Ser5P, Ser2P or unphosphorylated RNAP II CTD, show that the FluPolCTD interaction is direct and specific for Ser5 $\mathrm{P}^{29,152,153}$. The structure of the bat FluPol $_{\mathrm{A}}$ Ser5P CTD complex shows that highly conserved basic residues, in two distinct sites, directly interact with the phosphate groups of two Ser5P of the CTD (Figure 4) ${ }^{29}$. Moreover, FluPol $_{\mathrm{A}}$ mutants carrying single alanine mutants of any of these basic residues, thus partially disrupting the CTD interaction, display a strongly impaired transcriptional activity in the cellular context but not in vitro when a capped RNA primer is provided, suggesting that the FluPol-CTD provides access to nascent host cell RNAs for cap-snatching. Recombinant viruses carrying these mutations were highly attenuated and genetically unstable, but could acquire second site mutations that partially restored infectivity ${ }^{29}$.

The CTD binding patterns of polymerases from different influenza subtypes present common and distinct features (Figure 4). Similar to FluPol $_{\mathrm{A}}$, co-crystal structures of FluPol $_{\mathrm{B}}{ }^{29}$ and $\mathrm{FluPol}_{\mathrm{C}}{ }^{153}$ show bipartite CTD binding sites. In FluPol${ }_{\mathrm{A}}$, both binding sites (sites 1A and 2A) are on the PA C-terminal domain (PA-C) (Figure 4 left). In FluPol ${ }_{\mathrm{B}}$, site 1 is conserved (site 1B) while site $2 \mathrm{~B}$ is distinct from site $2 \mathrm{~A}$ and crosses over from PA-C to the

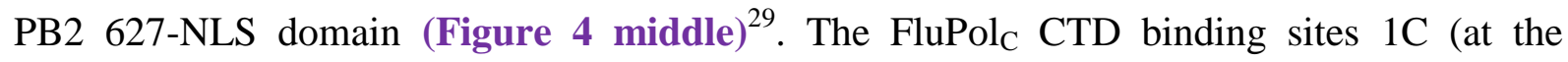
interface between P3-C and PB1) and 2C (on P3-C) are distinct from any of the sites observed in $\mathrm{FluPol}_{\mathrm{A}}$ and $\mathrm{FluPol}_{\mathrm{B}}(\text { Figure } 4 \text { right })^{153}$. A parallel can be drawn between the CTD binding strategies evolved by divergent influenza polymerases and the recruitment of capping enzymes from different species to RNAP II. Whereas, the capping enzymes from yeast, fungal and mammalian species directly interact with Ser5P RNAP II CTD repeats, the binding interfaces and the conformations of the bound CTD peptides differ between species ${ }^{85,86,154}$. A similar process of divergent evolution of CTD binding might have occurred for FluPol, as the 
influenza genera differ in host range ${ }^{155}$. Despite the general conservation of the CTD heptad repeats $^{37}$, subtle differences in degenerate residues of the RNAP II CTD might have an effect on FluPol binding and therefore might affect the cap-snatching efficiency. Additionally, the context of associated host factors of the FluPol-RNAP II complex may present host specificities, as seen for other host factors, which are essential for influenza replication ${ }^{155}$.

The binding of CTD mimicking peptides to FluPol indicates that the affinity of each individual interaction at site 1 or 2 is in the micromolar range. However, binding in one site increases the affinity to the other ${ }^{29}$. Avidity and cooperativity mechanisms therefore likely result in an overall high-affinity interaction between FluPol and the full-length CTD in the cellular context, although this association is likely to be highly dynamic. The CTD domain is located adjacent to the RNAP II mRNA exit tunnel ${ }^{102}$, thereby allowing the coordinate binding of proteins involved in post-transcriptional processing ${ }^{37}$. Therefore, it is plausible that binding of FluPol to a distal CTD repeat stimulates subsequent binding to a proximal repeat, looping out a long CTD stretch in between and thereby bringing FluPol closer to the RNAP II mRNA exit tunnel.

\section{3) The localisation and timing of cap-snatching}

\section{1) Intranuclear sites of RNAP II and FluPol transcription}

A prerequisite for efficient FluPol transcription is access to a constant supply of RNAP II derived nascent 5'-capped RNAs. Given that viral mRNAs can constitute up to $50 \%$ of the total mRNA in influenza-virus infected cells ${ }^{156}$, it is plausible that a highly efficient mechanism targets vRNPs, and especially incoming parental vRNPs, to specific subnuclear localisations enriched in actively transcribing RNAP II. However, so far there is no clear evidence for such a mechanism. 
Analyses of nuclear fractions with different nuclease sensitivity provided the first evidence that actively transcribed genes correspond to regions of "open chromatin", where DNA is not tightly bound to histones and is therefore more accessible to transcription factors $^{157}$. Based on microscopy and profiling of high salt fractions on fixed cells, it was proposed that active RNAP II transcription occurs at discrete sites in the nucleus named "transcription factories" that contain clusters of RNAP II and transcription factors tethered to the insoluble "nuclear matrix"158. Using a similar approach, influenza vRNPs were found to be associated to chromatin and components of the nuclear matrix ${ }^{159,160}$, and viral RNA synthesis was suggested to occur in the same insoluble subnuclear compartment ${ }^{161-163}$.

Later studies led to more dynamic models for the regulation of chromatin topology and RNAP II clustering that better account for rapid transcriptional gene activation in response to external stimuli. Chromatin remodelling was shown to be mediated by histone modifications such as acetylation ${ }^{164}$ or methylation ${ }^{165}$ and to play a central role in the regulation of gene expression ${ }^{166}$. The chromatin remodellers CHD1 and MORC3, which recognize transcriptionally active chromatin regions, were both found to bind FluPol and to enhance viral mRNA transcription ${ }^{149,167}$. It is possible that CHD1 and MORC3 target vRNPs to sites of open chromatin and active RNAP II transcription.

Recently, live-cell super-resolution microscopy revealed transient dynamic foci of RNAP II that are referred to as RNAP II condensates ${ }^{168,169}$. A growing body of evidence suggests that these foci are formed by liquid-liquid phase separation, which is established by multivalent interactions between proteins with low-complexity disordered regions $(\text { LCDRs })^{31,170,171}$. Transcription factors frequently possess $\mathrm{LCDRs}^{172}$, which can attract the Mediator complex and RNAP II, thereby concentrating transcription initiation factors at enhancer and promotor regions ${ }^{173,174}$. The CTD of RNAP II itself is an LCDR, which can undergo phase separation ${ }^{175-177}$ and is suggested to drive the establishment of Mediatorcontaining "promoter condensates" where transcription initiation occurs ${ }^{31,176,177}$. CTD 
phosphorylation enhances RNAP II incorporation into phase-separated droplets formed by $\mathrm{P}_{-\mathrm{TEFb}}{ }^{178}$ and major components of the splicing apparatus ${ }^{176}$. A condensate-based model of transcription was therefore proposed ${ }^{171}$, in which CTD phosphorylation drives RNAP II relocalisation from "promotor condensates" to "gene body condensates"31.

So far only a few studies have documented the behaviour of FluPol in live cells. Fluorescence recovery after photobleaching (FRAP) studies have shown that the nuclear mobility of transiently expressed vRNPs is increased upon RNAP II inhibition with $\alpha$-amanitin ${ }^{121}$. Single-particle analyses of incoming vRNPs demonstrated two distinct nuclear diffusion patterns corresponding to a simple and a restricted diffusion, respectively ${ }^{179}$. It is tempting to speculate that the FluPol binding preference for Ser5 phosphorylated CTD repeats drives the incorporation of vRNPs into "gene body condensates", therefore restricting their diffusion and providing access to nascent capped RNAs. Super-resolution microscopy studies of FluPol and its localisation relative to key phase-separating factors of the transcriptional machinery will be needed to explore this hypothesis.

\section{2) FluPol access to nascent capped RNAP II transcripts}

The preferential binding of FluPol to Ser5P CTD suggests that FluPol is recruited to the promoter-proximal region of RNAP II transcribed genes, as RNAP II Ser5P CTD is enriched around the transcription start site $(\mathrm{TSS})^{26,30}$. This model is supported by FluPol chromatin immunoprecipitation followed by DNA sequencing (ChIP-seq) analyses that show that FluPol exclusively binds to RNAP II associated DNA and preferentially to the TSS when compared to intragenic regions ${ }^{26}$. Viewed from a RNAP II perspective, the current mechanistic understanding of the regulation of RNAP II transcription is based on a variety of techniques $^{180}$. Mapping of global RNAP II genome occupancy by ChIP-seq ${ }^{181}$ or sequencing of nascent RNA associated with RNAP II ${ }^{182}$ have proven to be valuable tools. ChIP-seq analyses using antibodies to specific CTD modifications of RNAP II indicate that Ser5 is 
phosphorylated at the TSS, which is reversed during transcriptional elongation ${ }^{181,183,184}$. In contrast to ChIP-seq, mammalian native elongating transcript sequencing (mNET-seq) identifies the 3' end sequence of nascent RNA in the active site of RNAP II, thereby allowing single-nucleotide resolution mapping of RNAP II ${ }^{185,186}$. Compared to ChIP-seq, mNET-seq does not indicate a strong Ser5P CTD enrichment at the TSS but reveals high levels of Ser5P CTD in exons ${ }^{182,186}$. Indeed, accumulating evidence suggests that Ser5P CTD is not restricted to the TSS but is present during transcriptional elongation and is preferentially associated with splicing factors ${ }^{38,187-189}$. While the discrepancy between ChIP-seq and mNET-seq can be due to methodological differences and needs to be clarified, it raises the question of whether FluPol cap-snatching occurs exclusively at promotor proximal regions. Currently, knowledge about the distribution of FluPol along RNAP II genes is restricted to the housekeeping genes $\beta$-actin and dihydrofolate reductase ${ }^{26}$. FluPol association along genes which are preferentially used as substrates for cap-snatching such as snRNAs and other non-coding RNAs ${ }^{19,190,191}$ is unclear. Moreover, a specific inhibition of the transition of RNAP II from the initiation to elongation state, as previously suggested ${ }^{26}$, was not observed by mNET-seq in influenza infected cells ${ }^{151}$. The RNAP II occupancy rather progressively declines downstream of the TSS when compared to non-infected cells ${ }^{151}$. Therefore, further investigations are needed to gain deeper knowledge about the timing of FluPol cap-snatching in relation to the RNAP II transcription cycle. Genome-wide ChIP-seq analyses of the DNA association of FluPol might improve the understanding of the window of opportunity for FluPol cap-snatching. Moreover, a comprehensive understanding about the timing of cap-snatching could help identifying essential host factors associated with the cap-snatching complex, as each step of RNAP II transcription necessitates a specific set of transcription factors (Figure 2). 


\section{3) FluPol cap preference and competition with the host CBC complex}

Early studies on the influenza cap-snatching mechanism have shown that the viral polymerase has a preference for the cap 1 structure (Figure 3c) ${ }^{192,193}$. Moreover, it was demonstrated that influenza mRNAs preferentially start with an adenine ${ }^{19,190}$ of which a significant amount is $\mathrm{m}^{6}$-A-modified (Figure $3 \mathrm{f}^{13}$. Since CAPAM acts on CMTR1methylated cap 1 (Figure 3d) ${ }^{84}$, this suggests that cap-snatching occurs after CMTR1 and CAPAM have modified the nascent RNAP II transcript, although it cannot be ruled out that these modifications occur after the cap is snatched and released from the PB2 cap-binding domain early in viral transcription. Indeed recent structures of capped-RNA bound FluPol with either $\mathrm{A}$ or $\mathrm{G}$ as the first nucleotide cannot rationalise the preference for methylated cap substrates, although direct comparative measurements of affinity have not been made $5,9,22,194$. It is possible that the observed in vivo preference for cap 1 is not governed by specific recognition of the methylated ribose or base of the first nucleotide, but that FluPol is actively recruited to transcribing RNAP II after CMTR1 and CAPAM have modified the nascent transcript.

This model poses several questions related to the exact timing and regulation of the sequential capping reactions and FluPol cap-snatching. What signals cap completion and how does FluPol successfully compete with the host CBC for access to the completed cap? This is particularly puzzling as the $\mathrm{CBC}$ has a very high affinity to the cap ${ }^{195}$, certainly much higher than the cap affinity to the cap-binding domain alone ${ }^{18}$, although tethering FluPol in the vicinity of the nascent capped RNA can increase the apparent affinity. In the absence of FluPol, the normal sequence of events connecting cap completion to pause release is thought to be as follows. Nascent transcript capping coincides with promoter proximal pausing when RNAP II is associated with NELF and DSIF, and the capping enzymes are recruited via interactions with the Ser5P CTD and unphosphorylated SPT5 CTR (Figure 2b). Subsequent phosphorylation of NELF and DSIF by P-TEFb and recruitment of PAF is required for pause 
release and the transition to processive RNAP II elongation. But how is the action of P-TEFb coordinated with cap-completion and CBC binding? It has recently been shown by NELF depletion, that NELF regulates a first step in pause release and its loss allows RNAP II to advance to the +1 nucleosome dyad position in a $\mathrm{P}-\mathrm{TEFb}$ independent manner ${ }^{196}$. Importantly, NELF depletion correlates with significantly reduced CBC levels at promoter regions. That NELF has an important role in recruiting CBC to nascent capped transcripts is consistent with NELF directly interacting with CBC via the C-terminus of the NELF-E subunit ${ }^{71,197}$. This interaction enhances the affinity of the CBC for the cap 8 fold ${ }^{197}$. Thus, as capping progresses to the $\mathrm{m}^{7} \mathrm{G}$ methylation step (cap 0 ), the affinity of $\mathrm{CBC}$ for the modified 5 ' end of the transcript increases by 100-200 fold (Figure 3a-c) ${ }^{195}$ and is enhanced by the interaction with NELF in cis $^{197}$. There is further evidence that a direct interaction between the CBC and P-TEFb contributes to the latter's recruitment to paused RNAP II ${ }^{198}$. Consistent with this, knockdown of the $\mathrm{CBC}$ reduces $\mathrm{P}-\mathrm{TEFb}$ and Ser2P CTD occupancy at promoters, as well as in coding regions ${ }^{198}$. These interactions provide a causal connection between cap-completion, CBC binding and P-TEFb-mediated pause release. However, given that the affinity of the CBC for RNA with additional methylation at the first transcribed nucleotide is not much different from cap $0^{195}$, it is not clear how it is ensured that these modifications occur before $\mathrm{CBC}$ association.

The next question is how does FluPol interfere with this process to allow robust capsnatching, given that its affinity for 5'-capped RNA is substantially lower than that of CBC? A plausible answer is that FluPol somehow manages to block $\mathrm{CBC}$ recruitment and/or sterically blocks CBC access to nascent 5'-capped RNAP II transcripts, but how this is achieved is currently unknown. Moreover, this block is only temporary as NCBP1 does associate with viral mRNAs ${ }^{199}$. Possibilities are that FluPol forces dissociation of NELF or specifically prevents CBC recruitment by NELF-E or sequesters CBC in a way that it cannot bind 5'capped nascent RNA. Consistent with this, the subunits of the $\mathrm{CBC}$ were identified as 
interaction partners of the viral polymerase in proteomics-based interaction screenings (Table 1). However, it is unclear whether this interaction is direct or indirect. On the other hand, one study shows that P-TEFb can interact with FluPol and thereby enhances its interaction with Ser5P RNAP II CTD thus promoting viral transcription ${ }^{131}$. In this scenario, it is possible that FluPol inhibits both P-TEFb kinase activity as well as its interaction with the CBC.

\section{4) Concluding remarks}

Recent high-resolution structures of actively transcribing FluPol at different stages of the transcription cycle have led to significant advances in the understanding of this unique process $^{9,22}$. Similarly, a series of cryo-EM structures, corresponding to complexes of the early RNAP II transcription process, reveal details of the transition from the RNAP II promoter proximal paused to the elongation state ${ }^{53,102,103,200}$. While these advances form the basis for a detailed description of the coupled RNAP II - FluPol cap-snatching complex, central questions remain to be answered. To generate a more comprehensive model of FluPol capsnatching, it will be key to i) identify the host factors present in the active RNAP II - FluPol cap-snatching complex, ii) precisely define the time-window during RNAP II transcription when cap-snatching occurs and iii) determine the intranuclear localisation of cap-snatching. Aided by this information, it may be possible to determine the structure of an active capsnatching complex either using in situ cryo-tomography or by reconstitution in vitro.

It is well known that the interaction of FluPol with the Ser5P RNAP II CTD is essential for cap-snatching ${ }^{28,29}$. However, it remains to be determined whether this interaction is specific enough to precisely dock FluPol onto the emerging nascent capped RNA or whether, in analogy with the capping enzyme ${ }^{74}$, other direct or indirect protein-protein 
interactions are involved (Figure 5). The identified protein partners of FluPol, including, for instance, SPT5, the preferential association of FluPol with the Ser5P CTD and the need for cap completion prior to cap-snatching, suggest that the cap-snatching complex is assembled on the paused elongation state of RNAP II, but precisely what factors are present, and their phosphorylation status, remains to be determined. Moreover, recent genomic mapping of RNAP II have demonstrated that the Ser5P CTD is not only found in the promotor proximal region of RNAP II transcribed genes ${ }^{37}$, but is also abundant throughout the gene body and especially localised to splice sites ${ }^{182,186}$. This further suggests that additional interactions, other than simply Ser5P CTD binding, target FluPol to the paused RNAP II elongation complex. Another intriguing open question is how FluPol is able to robustly compete with the high affinity nuclear $\mathrm{CBC}$ for access to the completed 5' cap? It is possible that FluPol specifically inhibits, by an unknown mechanism, recruitment of $\mathrm{CBC}$ to the nascent capped RNA before cap-snatching, but, paradoxically, $\mathrm{CBC}$ is eventually recruited to viral mRNAs ${ }^{199}$. Binding of another viral protein, e.g. NS1 to the $\mathrm{CBC}^{125}$ or indirect interference with host factors related to RNAP II pausing and pause release, such as DSIF, NELF, TRIM28 or P-TEFb could be involved.

Another level of complexity has recently been added by the emergence of the condensate-based model of transcription, which proposes CTD phosphorylation-dependent RNAP II relocalisation from "promotor condensates" to "gene body condensates" 31,171 . It is unclear whether FluPol alone or in association with host-factors can undergo phase-separation and localises to these condensates (Figure 5). However, some FluPol interaction partners, like FUS $^{201}$, are known to promote phase separation, and others, like the ANP32 protein family (which however are more implicated in viral replication than transcription), contain large LCDRs $^{202}$. Studies on the subnuclear localisation, as well as the genomic association of FluPol will be needed to further define the model of FluPol cap-snatching in the context of subnuclear compartments. 
Cap-snatching represents an attractive target of antiviral intervention as illustrated by the recent development of inhibitors that target the PB2 cap-binding domain ${ }^{203}$ and the PA endonuclease domain ${ }^{204}$. The recently described CTD binding sites on FluPol possibly represent novel targets of antiviral intervention, even though inhibiting protein-protein interactions is challenging. However, as discussed in this review, it is likely that the FluPolCTD interaction does not represent the sole interface with the RNAP II transcription machinery. Therefore, it is of high interest to gain deeper knowledge about the cap-snatching process in order to identify novel targets for therapeutic intervention. 


\section{5) References}

1. Krammer, F. et al. Influenza. Nature Reviews Disease Primers (2018) doi:10.1038/s41572-018-0002-y.

2. Knipe, D. M. \& Howley, P. Fields virology: Sixth edition. Fields Virology: Sixth Edition (2013).

3. Eisfeld, A. J., Neumann, G. \& Kawaoka, Y. At the centre: Influenza A virus ribonucleoproteins. Nature Reviews Microbiology (2015) doi:10.1038/nrmicro3367.

4. Wandzik, J. M., Kouba, T. \& Cusack, S. Structure and Function of Influenza Polymerase. Cold Spring Harb. Perspect. Med. (2020) doi:10.1101/cshperspect.a038372.

5. Fan, H. et al. Structures of influenza A virus RNA polymerase offer insight into viral genome replication. Nature (2019) doi:10.1038/s41586-019-1530-7.

6. Pflug, A., Guilligay, D., Reich, S. \& Cusack, S. Structure of influenza A polymerase bound to the viral RNA promoter. Nature (2014) doi:10.1038/nature14008.

7. Reich, S. et al. Structural insight into cap-snatching and RNA synthesis by influenza polymerase. Nature (2014) doi:10.1038/nature14009.

8. Thierry, E. et al. Influenza Polymerase Can Adopt an Alternative Configuration Involving a Radical Repacking of PB2 Domains. Mol. Cell (2016) doi:10.1016/j.molcel.2015.11.016.

9. Wandzik, J. M. et al. A Structure-Based Model for the Complete Transcription Cycle of Influenza Polymerase. Cell (2020) doi:10.1016/j.cell.2020.03.061.

10. Deng, T., Vreede, F. T. \& Brownlee, G. G. Different De Novo Initiation Strategies Are Used by Influenza Virus RNA Polymerase on Its cRNA and Viral RNA Promoters during Viral RNA Replication. J. Virol. (2006) doi:10.1128/jvi.80.5.2337-2348.2006.

11. Oymans, J. \& te Velthuis, A. J. W. A Mechanism for Priming and Realignment during Influenza A Virus Replication. J. Virol. (2017) doi:10.1128/jvi.01773-17. 
12. Beaton, A. R. \& Krug, R. M. Selected host cell capped RNA fragments prime influenza viral RNA transcription in vivo. Nucleic Acids Res. (1981) doi:10.1093/nar/9.17.4423.

13. Krug, R. M., Morgan, M. A. \& Shatkin, A. J. Influenza viral mRNA contains internal N6-methyladenosine and 5'-terminal 7-methylguanosine in cap structures. J. Virol. (1976) doi:10.1128/jvi.20.1.45-53.1976.

14. Bercovich-Kinori, A. et al. A systematic view on influenza induced host shutoff. Elife (2016) doi:10.7554/eLife.18311.

15. Plotch, S. J., Tomasz, J. \& Krug, R. M. Absence of Detectable Capping and Methylating Enzymes in Influenza Virions. J. Virol. (1978) doi:10.1128/jvi.28.1.7583.1978.

16. Bouloy, M., Plotch, S. J. \& Krug, R. M. Globin mRNAs are primers for the transcription of influenza viral RNA in vitro. Proc. Natl. Acad. Sci. U. S. A. (1978) doi:10.1073/pnas.75.10.4886.

17. Plotch, S. J., Bouloy, M. \& Krug, R. M. Transfer of 5'-terminal cap of globin mRNA to influenza viral complementary RNA during transcription in vitro. Proc. Natl. Acad. Sci. U. S. A. (1979) doi:10.1073/pnas.76.4.1618.

18. Guilligay, D. et al. The structural basis for cap binding by influenza virus polymerase subunit PB2. Nat. Struct. Mol. Biol. (2008) doi:10.1038/nsmb.1421.

19. Clohisey, S. et al. Comprehensive Characterization of Transcriptional Activity during Influenza A Virus Infection Reveals Biases in Cap-Snatching of Host RNA Sequences. J. Virol. (2020) doi:10.1128/jvi.01720-19.

20. Dias, A. et al. The cap-snatching endonuclease of influenza virus polymerase resides in the PA subunit. Nature (2009) doi:10.1038/nature07745.

21. Poon, L. L. M., Pritlove, D. C., Fodor, E. \& Brownlee, G. G. Direct Evidence that the Poly(A) Tail of Influenza A Virus mRNA Is Synthesized by Reiterative Copying of a U Track in the Virion RNA Template. J. Virol. (1999) doi:10.1128/jvi.73.4.3473- 
3476.1999.

22. Kouba, T., Drncová, P. \& Cusack, S. Structural snapshots of actively transcribing influenza polymerase. Nat. Struct. Mol. Biol. (2019) doi:10.1038/s41594-019-0232-z.

23. Coloma, R. et al. Structural insights into influenza A virus ribonucleoproteins reveal a processive helical track as transcription mechanism. Nat. Microbiol. (2020) doi:10.1038/s41564-020-0675-3.

24. Peng, Q. et al. Structural insight into RNA synthesis by influenza D polymerase. Nat. Microbiol. (2019) doi:10.1038/s41564-019-0487-5.

25. Olschewski, S., Cusack, S. \& Rosenthal, M. The Cap-Snatching Mechanism of Bunyaviruses. Trends in Microbiology (2020) doi:10.1016/j.tim.2019.12.006.

26. Chan, A. Y., Vreede, F. T., Smith, M., Engelhardt, O. G. \& Fodor, E. Influenza virus inhibits RNA polymerase II elongation. Virology (2006) doi:10.1016/j.virol.2006.03.005.

27. Rott, R. \& Scholtissek, C. Specific inhibition of influenza replication by $\alpha$-amanitin. Nature (1970) doi:10.1038/228056a0.

28. Engelhardt, O. G., Smith, M. \& Fodor, E. Association of the Influenza A Virus RNADependent RNA Polymerase with Cellular RNA Polymerase II. J. Virol. (2005) doi:10.1128/jvi.79.9.5812-5818.2005.

29. Lukarska, M. et al. Structural basis of an essential interaction between influenza polymerase and Pol II CTD. Nature (2017) doi:10.1038/nature20594.

30. Walker, A. P. \& Fodor, E. Interplay between Influenza Virus and the Host RNA Polymerase II Transcriptional Machinery. Trends in Microbiology (2019) doi:10.1016/j.tim.2018.12.013.

31. Cramer, P. Organization and regulation of gene transcription. Nature (2019) doi:10.1038/s41586-019-1517-4.

32. Sun, Q., Hao, Q. \& Prasanth, K. V. Nuclear Long Noncoding RNAs: Key Regulators 
of Gene Expression. Trends in Genetics (2018) doi:10.1016/j.tig.2017.11.005.

33. Lee, Y. et al. MicroRNA genes are transcribed by RNA polymerase II. EMBO J. (2004) doi:10.1038/sj.emboj.7600385.

34. Matera, A. G. \& Wang, Z. A day in the life of the spliceosome. Nature Reviews Molecular Cell Biology (2014) doi:10.1038/nrm3742.

35. Kufel, J. \& Grzechnik, P. Small Nucleolar RNAs Tell a Different Tale. Trends in Genetics (2019) doi:10.1016/j.tig.2018.11.005.

36. Harlen, K. M. \& Churchman, L. S. The code and beyond: Transcription regulation by the RNA polymerase II carboxy-terminal domain. Nature Reviews Molecular Cell Biology (2017) doi:10.1038/nrm.2017.10.

37. Eick, D. \& Geyer, M. The RNA polymerase II carboxy-terminal domain (CTD) code. Chemical Reviews (2013) doi:10.1021/cr400071f.

38. Zaborowska, J., Egloff, S. \& Murphy, S. The pol II CTD: New twists in the tail. Nature Structural and Molecular Biology (2016) doi:10.1038/nsmb.3285.

39. Gupta, K., Sari-Ak, D., Haffke, M., Trowitzsch, S. \& Berger, I. Zooming in on Transcription Preinitiation. Journal of Molecular Biology (2016) doi:10.1016/j.jmb.2016.04.003.

40. Schilbach, S. et al. Structures of transcription pre-initiation complex with TFIIH and Mediator. Nature (2017) doi:10.1038/nature24282.

41. Kornberg, R. D. Mediator and the mechanism of transcriptional activation. Trends in Biochemical Sciences (2005) doi:10.1016/j.tibs.2005.03.011.

42. Soutourina, J. Transcription regulation by the Mediator complex. Nature Reviews Molecular Cell Biology (2018) doi:10.1038/nrm.2017.115.

43. Eychenne, T. et al. Functional interplay between Mediator and TFIIB in preinitiation complex assembly in relation to promoter architecture. Genes Dev. (2016) doi:10.1101/gad.285775.116. 
44. Nozawa, K., Schneider, T. R. \& Cramer, P. Core Mediator structure at $3.4 \AA$ extends model of transcription initiation complex. Nature (2017) doi:10.1038/nature22328.

45. Svejstrup, J. Q. et al. Evidence for a mediator cycle at the initiation of transcription. Proc. Natl. Acad. Sci. U. S. A. (1997) doi:10.1073/pnas.94.12.6075.

46. Wong, K. H., Jin, Y. \& Struhl, K. TFIIH Phosphorylation of the Pol II CTD Stimulates Mediator Dissociation from the Preinitiation Complex and Promoter Escape. Mol. Cell (2014) doi:10.1016/j.molcel.2014.03.024.

47. Core, L. \& Adelman, K. Promoter-proximal pausing of RNA polymerase II: A nexus of gene regulation. Genes and Development (2019) doi:10.1101/gad.325142.119.

48. Henriques, T. et al. Stable Pausing by RNA Polymerase II Provides an Opportunity to Target and Integrate Regulatory Signals. Mol. Cell (2013).

49. Rougvie, A. E. \& Lis, J. T. The RNA polymerase II molecule at the $5^{\prime}$ end of the uninduced hsp70 gene of D. melanogaster is transcriptionally engaged. Cell (1988) doi:10.1016/S0092-8674(88)91087-2.

50. Shao, W. \& Zeitlinger, J. Paused RNA polymerase II inhibits new transcriptional initiation. Nat. Genet. (2017) doi:10.1038/ng.3867.

51. Gilchrist, D. A. et al. Pausing of RNA polymerase II disrupts DNA-specified nucleosome organization to enable precise gene regulation. Cell (2010) doi:10.1016/j.cell.2010.10.004.

52. Bernecky, C., Plitzko, J. M. \& Cramer, P. Structure of a transcribing RNA polymerase II-DSIF complex reveals a multidentate DNA-RNA clamp. Nat. Struct. Mol. Biol. (2017) doi:10.1038/nsmb.3465.

53. Vos, S. M., Farnung, L., Urlaub, H. \& Cramer, P. Structure of paused transcription complex Pol II-DSIF-NELF. Nature (2018) doi:10.1038/s41586-018-0442-2.

54. Wada, T. et al. DSIF, a novel transcription elongation factor that regulates RNA polymerase II processivity, is composed of human Spt4 and Spt5 homologs. Genes 
Dev. (1998) doi:10.1101/gad.12.3.343.

55. Vos, S. M. et al. Architecture and RNA binding of the human negative elongation factor. Elife (2016) doi:10.7554/eLife.14981.

56. Yamaguchi, Y. et al. NELF, a multisubunit complex containing RD, cooperates with DSIF to repress RNA polymerase II elongation. Cell (1999) doi:10.1016/S00928674(00)80713-8.

57. Ehara, H. et al. Structure of the complete elongation complex of RNA polymerase II with basal factors. Science (80-. ). (2017) doi:10.1126/science.aan8552.

58. Yamada, T. et al. P-TEFb-mediated phosphorylation of hSpt5 C-terminal repeats is critical for processive transcription elongation. Mol. Cell (2006) doi:10.1016/j.molcel.2005.11.024.

59. Hartzog, G. A. \& Fu, J. The Spt4-Spt5 complex: A multi-faceted regulator of transcription elongation. Biochimica et Biophysica Acta - Gene Regulatory Mechanisms (2013) doi:10.1016/j.bbagrm.2012.08.007.

60. Palangat, M., Renner, D. B., Price, D. H. \& Landick, R. A negative elongation factor for human RNA polymerase II inhibits the anti-arrest transcript-cleavage factor TFIIS. Proc. Natl. Acad. Sci. U. S. A. (2005) doi:10.1073/pnas.0409405102.

61. Cheung, A. C. M. \& Cramer, P. Structural basis of RNA polymerase II backtracking, arrest and reactivation. Nature (2011) doi:10.1038/nature09785.

62. Chiu, Y. L. et al. Tat stimulates cotranscriptional capping of HIV mRNA. Mol. Cell (2002) doi:10.1016/S1097-2765(02)00630-5.

63. Rasmussen, E. B. \& Lis, J. T. In vivo transcriptional pausing and cap formation on three Drosophila heat shock genes. Proc. Natl. Acad. Sci. U. S. A. (1993) doi:10.1073/pnas.90.17.7923.

64. Tome, J. M., Tippens, N. D. \& Lis, J. T. Single-molecule nascent RNA sequencing identifies regulatory domain architecture at promoters and enhancers. Nat. Genet. 
(2018) doi:10.1038/s41588-018-0234-5.

65. Galloway, A. \& Cowling, V. H. mRNA cap regulation in mammalian cell function and fate. Biochimica et Biophysica Acta - Gene Regulatory Mechanisms (2019) doi:10.1016/j.bbagrm.2018.09.011.

66. Izaurralde, E. et al. A nuclear cap binding protein complex involved in pre-mRNA splicing. Cell (1994) doi:10.1016/0092-8674(94)90530-4.

67. Mazza, C., Ohno, M., Segref, A., Mattaj, I. W. \& Cusack, S. Crystal structure of the human nuclear cap binding complex. Mol. Cell (2001) doi:10.1016/S10972765(01)00299-4.

68. Pabis, M. et al. The nuclear cap-binding complex interacts with the U4/U6-U5 trisnRNP and promotes spliceosome assembly in mammalian cells. RNA (2013) doi:10.1261/rna.037069.112.

69. Ohno, M., Segref, A., Bachi, A., Wilm, M. \& Mattaj, I. W. PHAX, a mediator of U snRNA nuclear export whose activity is regulated by phosphorylation. Cell (2000) doi:10.1016/S0092-8674(00)80829-6.

70. Andersen, P. R. et al. The human cap-binding complex is functionally connected to the nuclear RNA exosome. Nat. Struct. Mol. Biol. (2013) doi:10.1038/nsmb.2703.

71. Narita, T. et al. NELF Interacts with CBC and Participates in $3^{\prime}$ End Processing of Replication-Dependent Histone mRNAs. Mol. Cell (2007) doi:10.1016/j.molcel.2007.04.011.

72. Muthukrishnan, S. et al. mRNA methylation and protein synthesis in extracts from embryos of brine shrimp, Artemia salina. J. Biol. Chem. (1975).

73. Cowling, V. H. \& Cole, M. D. Myc regulation of mRNA cap methylation. Genes and Cancer (2010) doi:10.1177/1947601910378025.

74. Martinez-Rucobo, F. W. et al. Molecular Basis of Transcription-Coupled Pre-mRNA Capping. Mol. Cell (2015) doi:10.1016/j.molcel.2015.04.004. 
75. Yue, Z. et al. Mammalian capping enzyme complements mutant Saccharomyces cerevisiae lacking mRNA guanylyltransferase and selectively binds the elongating form of RNA polymerase II. Proc. Natl. Acad. Sci. U. S. A. (1997) doi:10.1073/pnas.94.24.12898.

76. Varshney, D. et al. Molecular basis of RNA guanine-7 methyltransferase (RNMT) activation by RAM. Nucleic Acids Res. (2016) doi:10.1093/nar/gkw637.

77. Shimotohno, K., Kodama, Y., Hashimoto, J. \& Miura, K. I. Importance of 5'-terminal blocking structure to stabilize mRNA in eukaryotic protein synthesis. Proc. Natl. Acad. Sci. U. S. A. (1977) doi:10.1073/pnas.74.7.2734.

78. Bélanger, F., Stepinski, J., Darzynkiewicz, E. \& Pelletier, J. Characterization of hMTr1, a human Cap1 2'-O-ribose methyltransferase. J. Biol. Chem. (2010) doi:10.1074/jbc.M110.155283.

79. Daffis, S. et al. 2'-O methylation of the viral mRNA cap evades host restriction by IFIT family members. Nature (2010) doi:10.1038/nature09489.

80. Devarkar, S. C. et al. Structural basis for $\mathrm{m} 7 \mathrm{G}$ recognition and 2'-O-methyl discrimination in capped RNAs by the innate immune receptor RIG-I. Proc. Natl. Acad. Sci. U. S. A. (2016) doi:10.1073/pnas.1515152113.

81. Werner, M. et al. 2'-O-ribose methylation of cap2 in human: Function and evolution in a horizontally mobile family. Nucleic Acids Res. (2011) doi:10.1093/nar/gkr038.

82. Furuichi, Y. et al. Methylated, blocked 5' termini in HeLa cell mRNA. Proc. Natl. Acad. Sci. U. S. A. (1975) doi:10.1073/pnas.72.5.1904.

83. Perry, R. P. \& Kelley, D. E. Kinetics of formation of 5' terminal caps in mRNA. Cell (1976) doi:10.1016/0092-8674(76)90156-2.

84. Akichika, S. et al. Cap-specific terminal N 6 -methylation of RNA by an RNA polymerase II-associated methyltransferase. Science (80-. ). (2019) doi:10.1126/science.aav0080. 
85. Fabrega, C., Shen, V., Shuman, S. \& Lima, C. D. Structure of an mRNA capping enzyme bound to the phosphorylated carboxy-terminal domain of RNA polymerase II. Mol. Cell (2003) doi:10.1016/S1097-2765(03)00187-4.

86. Ghosh, A., Shuman, S. \& Lima, C. D. Structural Insights to How Mammalian Capping Enzyme Reads the CTD Code. Mol. Cell (2011) doi:10.1016/j.molcel.2011.06.001.

87. Ho, C. K. \& Shuman, S. Distinct roles for CTD Ser-2 and Ser-5 phosphorylation in the recruitment and allosteric activation of mammalian mRNA capping enzyme. Mol. Cell (1999) doi:10.1016/S1097-2765(00)80468-2.

88. McCracken, S. et al. 5'-Capping enzymes are targeted to pre-mRNA by binding to the phosphorylated carboxy-terminal domain of RNA polymerase II. Genes Dev. (1997) doi:10.1101/gad.11.24.3306.

89. Mandal, S. S. et al. Functional interactions of RNA-capping enzyme with factors that positively and negatively regulate promoter escape by RNA polymerase II. Proc. Natl. Acad. Sci. U. S. A. (2004) doi:10.1073/pnas.0401493101.

90. Schneider, S., Pei, Y., Shuman, S. \& Schwer, B. Separable Functions of the Fission Yeast Spt5 Carboxyl-Terminal Domain (CTD) in Capping Enzyme Binding and Transcription Elongation Overlap with Those of the RNA Polymerase II CTD. Mol. Cell. Biol. (2010) doi:10.1128/mcb.00116-10.

91. Noe Gonzalez, M., Sato, S., Tomomori-Sato, C., Conaway, J. W. \& Conaway, R. C. CTD-dependent and -independent mechanisms govern co-transcriptional capping of Pol II transcripts. Nat. Commun. (2018) doi:10.1038/s41467-018-05923-w.

92. Haline-Vaz, T., Lima Silva, T. C. \& Zanchin, N. I. T. The human interferon-regulated ISG95 protein interacts with RNA polymerase II and shows methyltransferase activity. Biochem. Biophys. Res. Commun. (2008) doi:10.1016/j.bbrc.2008.05.137.

93. Li, Y., Liu, M., Chen, L. F. \& Chen, R. P-TEFb: Finding its ways to release promoterproximally paused RNA polymerase II. Transcription (2018) 
doi:10.1080/21541264.2017.1281864.

94. Marshall, N. F. \& Price, D. H. Purification of P-TEFb, a transcription factor required for the transition into productive elongation. J. Biol. Chem. (1995) doi:10.1074/jbc.270.21.12335.

95. Yik, J. H. N. et al. Inhibition of P-TEFb (CDK9/cyclin T) kinase and RNA polymerase II transcription by the coordinated actions of HEXIM1 and 7SK snRNA. Mol. Cell (2003) doi:10.1016/S1097-2765(03)00388-5.

96. Moon, K. J. et al. The bromodomain protein Brd4 is a positive regulatory component of P-TEFb and stimulates RNA polymerase II-dependent transcription. Mol. Cell (2005) doi:10.1016/j.molcel.2005.06.027.

97. Chen, R. et al. PP2B and PP1 $\alpha$ cooperatively disrupt 7SK snRNP to release $\mathrm{P}-\mathrm{TEFb}$ for transcription in response to $\mathrm{Ca} 2+$ signaling. Genes Dev. (2008) doi:10.1101/gad.1636008.

98. $\mathrm{Hu}, \mathrm{X}$. et al. Histone cross-talk connects protein phosphatase $1 \alpha(\mathrm{PP} 1 \alpha)$ and histone deacetylase (HDAC) pathways to regulate the functional transition of bromodomaincontaining 4 (BRD4) for inducible gene expression. J. Biol. Chem. (2014) doi:10.1074/jbc.M114.570812.

99. McNamara, R. P. et al. KAP1 Recruitment of the 7SK snRNP Complex to Promoters Enables Transcription Elongation by RNA Polymerase II. Mol. Cell (2016) doi:10.1016/j.molcel.2015.11.004.

100. Fujinaga, K. et al. Dynamics of Human Immunodeficiency Virus Transcription: PTEFb Phosphorylates RD and Dissociates Negative Effectors from the Transactivation Response Element. Mol. Cell. Biol. (2004) doi:10.1128/mcb.24.2.787-795.2004.

101. Schüller, R. et al. Heptad-Specific Phosphorylation of RNA Polymerase II CTD. Mol. Cell (2016) doi:10.1016/j.molcel.2015.12.003.

102. Vos, S. M. et al. Structure of activated transcription complex Pol II-DSIF-PAF-SPT6. 
Nature (2018) doi:10.1038/s41586-018-0440-4.

103. Vos, S. M., Farnung, L., Linden, A., Urlaub, H. \& Cramer, P. Structure of complete Pol II-DSIF-PAF-SPT6 transcription complex reveals RTF1 allosteric activation. Nat. Struct. Mol. Biol. (2020) doi:10.1038/s41594-020-0437-1.

104. Liu, X., Farnung, L., Wigge, C. \& Cramer, P. Cryo-EM structure of a mammalian RNA polymerase II elongation complex inhibited by $\alpha$-amanitin. J. Biol. Chem. (2018) doi:10.1074/jbc.RA118.002545.

105. Sobell, H. M. Actinomycin and DNA transcription. Proc. Natl. Acad. Sci. U. S. A. (1985) doi:10.1073/pnas.82.16.5328.

106. Reich, E., Franklin, R. M., Shatkin, A. J. \& Tatum, E. L. Effect of actinomycin D on cellular nucleic acid synthesis and virus production. Science (80-. ). (1961) doi:10.1126/science.134.3478.556.

107. Barry, R. D. The effects of actinomycin D and ultraviolet irradiation on the production of fowl plague virus. Virology (1964) doi:10.1016/0042-6822(64)90208-9.

108. Barry, R. D., Ives, D. R. \& Cruickshank, J. G. Participation of deoxyribonucleic acid in the multiplication of influenza virus. Nature (1962) doi:10.1038/1941139a0.

109. Mahy, B. W., Hastie, N. D. \& Armstrong, S. J. Inhibition of influenza virus replication by -amanitin: mode of action. Proc. Natl. Acad. Sci. U. S. A. (1972) doi:10.1073/pnas.69.6.1421.

110. Lamb, R. A. \& Choppin, P. W. Synthesis of influenza virus polypeptides in cells resistant to alpha-amanitin: evidence for the involvement of cellular RNA polymerase II in virus replication. J. Virol. (1977) doi:10.1128/jvi.23.3.816-819.1977.

111. Spooner, L. L. R. \& Barry, R. D. Participation of DNA-dependent RNA polymerase II in replication of influenza viruses. Nature (1977) doi:10.1038/268650a0.

112. Vreede, F. T., Ng, A. K.-L., Shaw, P.-C. \& Fodor, E. Stabilization of Influenza Virus Replication Intermediates Is Dependent on the RNA-Binding but Not the Homo- 
Oligomerization Activity of the Viral Nucleoprotein. J. Virol. (2011) doi:10.1128/jvi.00695-11.

113. Mark, G. E., Taylor, J. M., Broni, B. \& Krug, R. M. Nuclear Accumulation of Influenza Viral RNA Transcripts and the Effects of Cycloheximide, Actinomycin D, and $\alpha$-Amanitin. J. Virol. (1979) doi:10.1128/jvi.29.2.744-752.1979.

114. Tamm, I., Folkers, K., Shunk, C. H. \& Horsfall, F. L. Inhibition of influenza virus multiplication by $\mathrm{N}$-glycosides of benzimidazoles-N. J. Exp. Med. (1954) doi:10.1084/jem.99.3.227.

115. Perwitasari, O., Yan, X., O’Donnell, J., Johnson, S. \& Tripp, R. A. Repurposing kinase inhibitors as antiviral agents to control influenza a virus replication. Assay Drug Dev. Technol. (2015) doi:10.1089/adt.2015.0003.drrr.

116. Bensaude, O. Inhibiting eukaryotic transcription: Which compound to choose? How to evaluate its activity? Transcription (2011) doi:10.4161/trns.2.3.16172.

117. Chao, S. H. \& Price, D. H. Flavopiridol Inactivates P-TEFb and Blocks Most RNA Polymerase II Transcription in Vivo. J. Biol. Chem. (2001) doi:10.1074/jbc.M102306200.

118. Sordet, O. et al. RNA polymerase II is Hyperphopshorylated in Response to Topoisomerase I-DNA Cleavage Complexes and is Associated with transcription-and BRCA1-Dependent Degradation of Topoisomerase I. J. Mol. Biol (2009) doi:10.1016/j.jmb.2008.06.028.RNA.

119. Yamaguchi, Y., Wada, T. \& Handa, H. Interplay between positive and negative elongation factors: Drawing a new view of DRB. Genes to Cells (1998) doi:10.1046/j.1365-2443.1998.00162.x.

120. Amorim, M. J., Read, E. K., Dalton, R. M., Medcalf, L. \& Digard, P. Nuclear export of influenza A virus mRNAs requires ongoing RNA polymerase II activity. Traffic (2007) doi:10.1111/j.1600-0854.2006.00507.x. 
121. Loucaides, E. M. et al. Nuclear dynamics of influenza A virus ribonucleoproteins revealed by live-cell imaging studies. Virology (2009) doi:10.1016/j.virol.2009.08.015.

122. Li, B. et al. Genome-wide CRISPR screen identifies host dependency factors for influenza A virus infection. Nat. Commun. (2020) doi:10.1038/s41467-019-13965-x.

123. Tripathi, S. et al. Meta- and Orthogonal Integration of Influenza 'oMICs' Data Defines a Role for UBR4 in Virus Budding. Cell Host Microbe (2015) doi:10.1016/j.chom.2015.11.002.

124. Bradel-Tretheway, B. G. et al. Comprehensive Proteomic Analysis of Influenza Virus Polymerase Complex Reveals a Novel Association with Mitochondrial Proteins and RNA Polymerase Accessory Factors. J. Virol. (2011) doi:10.1128/jvi.00496-11.

125. Heaton, N. S. et al. Targeting Viral Proteostasis Limits Influenza Virus, HIV, and Dengue Virus Infection. Immunity (2016) doi:10.1016/j.immuni.2015.12.017.

126. Hubel, P. et al. A protein-interaction network of interferon-stimulated genes extends the innate immune system landscape. Nat. Immunol. (2019) doi:10.1038/s41590-0190323-3

127. Chen, Y. et al. DSIF, the Paf1 complex, and Tat-SF1 have nonredundant, cooperative roles in RNA polymerase II elongation. Genes Dev. (2009) doi:10.1101/gad.1834709.

128. Kwak, Y. T. et al. Methylation of SPT5 regulates its interaction with RNA polymerase II and transcriptional elongation properties. Mol. Cell (2003) doi:10.1016/S10972765(03)00101-1.

129. Mayer, D. et al. Identification of cellular interaction partners of the influenza virus ribonucleoprotein complex and polymerase complex using proteomic-based approaches. J. Proteome Res. (2007) doi:10.1021/pr060432u.

130. Tafforeau, L. et al. Generation and Comprehensive Analysis of an Influenza Virus Polymerase Cellular Interaction Network. J. Virol. (2011) doi:10.1128/jvi.02651-10.

131. Zhang, J., Li, G. \& Ye, X. Cyclin T1/CDK9 Interacts with Influenza A Virus 
Polymerase and Facilitates Its Association with Cellular RNA Polymerase II. J. Virol. (2010) doi:10.1128/jvi.01696-10.

132. Bunch, H. et al. TRIM28 regulates RNA polymerase II promoter-proximal pausing and pause release. Nat. Struct. Mol. Biol. (2014) doi:10.1038/nsmb.2878.

133. Ma, X. et al. TRIM28 promotes HIV-1 latency by SUMOylating CDK9 and inhibiting P-TEFb. Elife (2019) doi:10.7554/eLife.42426.

134. Brass, A. L. et al. The IFITM Proteins Mediate Cellular Resistance to Influenza A H1N1 Virus, West Nile Virus, and Dengue Virus. Cell (2009) doi:10.1016/j.cell.2009.12.017.

135. König, R. et al. Human host factors required for influenza virus replication. Nature (2010) doi:10.1038/nature08699.

136. Schmidt, N. et al. An influenza virus-triggered SUMO switch orchestrates co-opted endogenous retroviruses to stimulate host antiviral immunity. Proc. Natl. Acad. Sci. U. S. A. (2019) doi:10.1073/pnas.1907031116.

137. Watanabe, T. et al. Influenza virus-host interactome screen as a platform for antiviral drug development. Cell Host Microbe (2014) doi:10.1016/j.chom.2014.11.002.

138. Krischuns, T. et al. Phosphorylation of TRIM28 Enhances the Expression of IFN- $\beta$ and Proinflammatory Cytokines During HPAIV Infection of Human Lung Epithelial Cells. Front. Immunol. (2018) doi:10.3389/fimmu.2018.02229.

139. Wang, Z. et al. Establishment of a high-throughput assay to monitor influenza a virus RNA transcription and replication. PLoS One (2015) doi:10.1371/journal.pone.0133558.

140. Karlas, A. et al. Genome-wide RNAi screen identifies human host factors crucial for influenza virus replication. Nature (2010) doi:10.1038/nature08760.

141. Shapira, S. D. et al. A Physical and Regulatory Map of Host-Influenza Interactions Reveals Pathways in H1N1 Infection. Cell (2009) doi:10.1016/j.cell.2009.12.018. 
142. Bortz, E. et al. Host- and Strain-Specific Regulation of Influenza Virus Polymerase. Regulation (2011) doi:10.1128/mBio.00151-11.Invited.

143. Westera, L. et al. Poly-ADP Ribosyl Polymerase 1 (PARP1) Regulates Influenza A Virus Polymerase. Adv. Virol. (2019) doi:10.1155/2019/8512363.

144. Naito, T. et al. An influenza virus replicon system in yeast identified Tat-SF1 as a stimulatory host factor for viral RNA synthesis. Proc. Natl. Acad. Sci. U. S. A. (2007) doi:10.1073/pnas.0705856104.

145. Tran, A. T. et al. Knockdown of specific host factors protects against influenza virusinduced cell death. Cell Death Dis. (2013) doi:10.1038/cddis.2013.296.

146. York, A., Hutchinson, E. C. \& Fodor, E. Interactome Analysis of the Influenza A Virus Transcription/Replication Machinery Identifies Protein Phosphatase 6 as a Cellular Factor Required for Efficient Virus Replication. J. Virol. (2014) doi:10.1128/jvi.0181314.

147. Karim, M. et al. Nonproteolytic K29-linked ubiquitination of the PB2 replication protein of influenza a viruses by proviral cullin 4-based E3 ligases. MBio (2020) doi:10.1128/mBio.00305-20.

148. Alfonso, R. et al. CHD6 chromatin remodeler is a negative modulator of influenza virus replication that relocates to inactive chromatin upon infection. Cell. Microbiol. (2011) doi:10.1111/j.1462-5822.2011.01679.x.

149. Marcos-Villar, L., Pazo, A. \& Nieto, A. Influenza Virus and Chromatin: Role of the CHD1 Chromatin Remodeler in the Virus Life Cycle. J. Virol. (2016) doi:10.1128/jvi.00053-16.

150. Rialdi, A. et al. The RNA Exosome Syncs IAV-RNAPII Transcription to Promote Viral Ribogenesis and Infectivity. Cell (2017) doi:10.1016/j.cell.2017.04.021.

151. Bauer, D. L. V. et al. Influenza Virus Mounts a Two-Pronged Attack on Host RNA Polymerase II Transcription. Cell Rep. (2018) doi:10.1016/j.celrep.2018.04.047. 
152. Martínez-Alonso, M., Hengrung, N. \& Fodor, E. RNA-Free and RibonucleoproteinAssociated Influenza Virus Polymerases Directly Bind the Serine-5-Phosphorylated Carboxyl-Terminal Domain of Host RNA Polymerase II. J. Virol. (2016) doi:10.1128/jvi.00494-16.

153. Serna Martin, I. et al. A Mechanism for the Activation of the Influenza Virus Transcriptase. Mol. Cell (2018) doi:10.1016/j.molcel.2018.05.011.

154. Doamekpor, S. K., Sanchez, A. M., Schwer, B., Shuman, S. \& Lima, C. D. How an mRNA capping enzyme reads distinct RNA polymerase II and Spt5 CTD phosphorylation codes. Genes Dev. (2014) doi:10.1101/gad.242768.114.

155. Long, J. S., Mistry, B., Haslam, S. M. \& Barclay, W. S. Host and viral determinants of influenza A virus species specificity. Nature Reviews Microbiology (2019) doi:10.1038/s41579-018-0115-z.

156. Russell, A. B., Trapnell, C. \& Bloom, J. D. Extreme heterogeneity of influenza virus infection in single cells. Elife (2018) doi:10.7554/eLife.32303.

157. Levy, A. \& Noll, M. Chromatin fine structure of active and repressed genes. Nature (1981) doi:10.1038/289198a0.

158. Sutherland, H. \& Bickmore, W. A. Transcription factories: Gene expression in unions? Nature Reviews Genetics (2009) doi:10.1038/nrg2592.

159. Chase, G. P. et al. Influenza virus ribonucleoprotein complexes gain preferential access to cellular export machinery through chromatin targeting. PLoS Pathog. (2011) doi:10.1371/journal.ppat.1002187.

160. Bukrinskaya, A. G., Vorkunova, N. K., Kornilayeva, G. V. \& Narmanbetova, R. A. Influenza virus uncoating in infected cells and effect of rimantadine. J. Gen. Virol. (1982) doi:10.1099/0022-1317-60-1-49.

161. Jackson, D. A., Caton, A. J., McCready, S. J. \& Cook, P. R. Influenza virus RNA is synthesized at fixed sites in the nucleus. Nature (1982) doi:10.1038/296366a0. 
162. López-Turiso, J., Martínez, C., Toshiki, T. \& Ortín, J. The synthesis of influenza virus negative-strand RNA takes place in insoluble complexes present in the nuclear matrix fraction. Virus Res. (1990) doi:10.1016/0168-1702(90)90056-H.

163. Takizawa, N., Watanabe, K., Nouno, K., Kobayashi, N. \& Nagata, K. Association of functional influenza viral proteins and RNAs with nuclear chromatin and subchromatin structure. Microbes Infect. (2006) doi:10.1016/j.micinf.2005.10.005.

164. Marmorstein, R. \& Zhou, M. M. Writers and readers of histone acetylation: Structure, mechanism, and inhibition. Cold Spring Harb. Perspect. Biol. (2014) doi:10.1101/cshperspect.a018762.

165. Hyun, K., Jeon, J., Park, K. \& Kim, J. Writing, erasing and reading histone lysine methylations. Experimental and Molecular Medicine (2017) doi:10.1038/emm.2017.11.

166. Lawrence, M., Daujat, S. \& Schneider, R. Lateral Thinking: How Histone Modifications Regulate Gene Expression. Trends in Genetics (2016) doi:10.1016/j.tig.2015.10.007.

167. Ver, L. S., Marcos-Villar, L., Landeras-Bueno, S., Nieto, A. \& Ortín, J. The Cellular Factor NXP2/MORC3 Is a Positive Regulator of Influenza Virus Multiplication. $J$. Virol. (2015) doi:10.1128/jvi.01530-15.

168. Cho, W. K. et al. Mediator and RNA polymerase II clusters associate in transcriptiondependent condensates. Science (80-. ). (2018) doi:10.1126/science.aar4199.

169. Cisse, I. I. et al. Real-time dynamics of RNA polymerase II clustering in live human cells. Science (80-. ). (2013) doi:10.1126/science.1239053.

170. Boeynaems, S. et al. Protein Phase Separation: A New Phase in Cell Biology. Trends in Cell Biology (2018) doi:10.1016/j.tcb.2018.02.004.

171. Hnisz, D., Shrinivas, K., Young, R. A., Chakraborty, A. K. \& Sharp, P. A. A Phase $\begin{array}{llllll}\text { Separation } & \text { Model } & \text { for } & \text { Transcriptional }\end{array}$ 
doi:10.1016/j.cell.2017.02.007.

172. Liu, J. et al. Intrinsic disorder in transcription factors. Biochemistry (2006) doi:10.1021/bi0602718.

173. Boija, A. et al. Transcription Factors Activate Genes through the Phase-Separation Capacity of Their Activation Domains. Cell (2018) doi:10.1016/j.cell.2018.10.042.

174. Chong, S. et al. Imaging dynamic and selective low-complexity domain interactions that control gene transcription. Science (80-. ). (2018) doi:10.1126/science.aar2555.

175. Boehning, M. et al. RNA polymerase II clustering through carboxy-terminal domain phase separation. Nat. Struct. Mol. Biol. (2018) doi:10.1038/s41594-018-0112-y.

176. Guo, Y. E. et al. Pol II phosphorylation regulates a switch between transcriptional and splicing condensates. Nature (2019) doi:10.1038/s41586-019-1464-0.

177. Kwon, I. et al. Phosphorylation-regulated binding of RNA polymerase ii to fibrous polymers of low-complexity domains. Cell (2014) doi:10.1016/j.cell.2014.01.002.

178. Lu, H. et al. Phase-separation mechanism for C-terminal hyperphosphorylation of RNA polymerase II. Nature (2018) doi:10.1038/s41586-018-0174-3.

179. Qin, C. et al. Real-time dissection of dynamic uncoating of individual influenza viruses. Proc. Natl. Acad. Sci. U. S. A. (2019) doi:10.1073/pnas.1812632116.

180. Wissink, E. M., Vihervaara, A., Tippens, N. D. \& Lis, J. T. Nascent RNA analyses: tracking transcription and its regulation. Nature Reviews Genetics (2019) doi:10.1038/s41576-019-0159-6.

181. Milligan, L. et al. Strand- specific, high- resolution mapping of modified RNA polymerase II. Mol. Syst. Biol. (2016) doi:10.15252/msb.20166869.

182. Nojima, T. et al. RNA Polymerase II Phosphorylated on CTD Serine 5 Interacts with the Spliceosome during Co-transcriptional Splicing. Mol. Cell (2018) doi:10.1016/j.molcel.2018.09.004.

183. Bataille, A. R. et al. A Universal RNA Polymerase II CTD Cycle Is Orchestrated by 
Complex Interplays between Kinase, Phosphatase, and Isomerase Enzymes along Genes. Mol. Cell (2012) doi:10.1016/j.molcel.2011.11.024.

184. Chapman, R. D. et al. Transcribing RNA polymerase II is phosphorylated at CTD residue serine-7. Science (80-. ). (2007) doi:10.1126/science.1145977.

185. Churchman, L. S. \& Weissman, J. S. Nascent transcript sequencing visualizes transcription at nucleotide resolution. Nature (2011) doi:10.1038/nature09652.

186. Nojima, T. et al. Mammalian NET-seq reveals genome-wide nascent transcription coupled to RNA processing. Cell (2015) doi:10.1016/j.cell.2015.03.027.

187. Batsché, E., Yaniv, M. \& Muchardt, C. The human SWI/SNF subunit Brm is a regulator of alternative splicing. Nat. Struct. Mol. Biol. (2006) doi:10.1038/nsmb1030.

188. Harlen, K. M. et al. Comprehensive RNA Polymerase II Interactomes Reveal Distinct and Varied Roles for Each Phospho-CTD Residue. Cell Rep. (2016) doi:10.1016/j.celrep.2016.05.010.

189. Prudêncio, P., Rebelo, K., Grosso, A. R., Martinho, R. G. \& Carmo-Fonseca, M. Analysis of Mammalian Native Elongating Transcript sequencing (mNET-seq) highthroughput data. Methods (2019) doi:10.1016/j.ymeth.2019.09.003.

190. Gu, W. et al. Influenza A virus preferentially snatches noncoding RNA caps. RNA (2015) doi:10.1261/rna.054221.115.

191. Koppstein, D., Ashour, J. \& Bartel, D. P. Sequencing the cap-snatching repertoire of H1N1 influenza provides insight into the mechanism of viral transcription initiation. Nucleic Acids Res. (2015) doi:10.1093/nar/gkv333.

192. Bouloy, M., Plotch, S. J. \& Krug, R. M. Both the 7-methyl and the 2'-O-methyl groups in the cap of mRNA strongly influence its ability to act as primer for influenza virus RNA transcription. Proc. Natl. Acad. Sci. U. S. A. (1980) doi:10.1073/pnas.77.7.3952.

193. Wakai, C., Iwama, M., Mizumoto, K. \& Nagata, K. Recognition of Cap Structure by Influenza B Virus RNA Polymerase Is Less Dependent on the Methyl Residue than 
Recognition by Influenza A Virus Polymerase. J. Virol. (2011) doi:10.1128/jvi.0237510.

194. Pflug, A. et al. Capped RNA primer binding to influenza polymerase and implications for the mechanism of cap-binding inhibitors. Nucleic Acids Res. (2018) doi:10.1093/nar/gkx1210.

195. Worch, R. et al. Specificity of recognition of mRNA 5' cap by human nuclear capbinding complex. RNA (2005) doi:10.1261/rna.2850705.

196. Aoi, Y. et al. NELF Regulates a Promoter-Proximal Step Distinct from RNA Pol II Pause-Release. Mol. Cell (2020) doi:10.1016/j.molcel.2020.02.014.

197. Schulze, W. M. \& Cusack, S. Structural basis for mutually exclusive co-transcriptional nuclear cap-binding complexes with either NELF-E or ARS2. Nat. Commun. (2017) doi:10.1038/s41467-017-01402-w.

198. Lenasi, T., Peterlin, B. M. \& Barboric, M. Cap-binding protein complex links premRNA capping to transcription elongation and alternative splicing through positive transcription elongation factor $\mathrm{b}$ (P-TEFb). J. Biol. Chem. (2011) doi:10.1074/jbc.M111.235077.

199. Bier, K., York, A. \& Fodor, E. Cellular cap-binding proteins associate with influenza virus mRNAs. J. Gen. Virol. (2011) doi:10.1099/vir.0.029231-0.

200. Farnung, L., Vos, S. M. \& Cramer, P. Structure of transcribing RNA polymerase IInucleosome complex. Nat. Commun. (2018) doi:10.1038/s41467-018-07870-y.

201. Qamar, S. et al. FUS Phase Separation Is Modulated by a Molecular Chaperone and Methylation of Arginine Cation- $\pi$ Interactions. Cell (2018) doi:10.1016/j.cell.2018.03.056.

202. Reilly, P. T., Yu, Y., Hamiche, A. \& Wang, L. Cracking the ANP32 whips: Important functions, unequal requirement, and hints at disease implications. BioEssays (2014) doi:10.1002/bies.201400058. 
203. Byrn, R. A. et al. Preclinical activity of VX-787, a first-in-class, orally bioavailable inhibitor of the influenza virus polymerase PB2 subunit. Antimicrob. Agents Chemother. (2015) doi:10.1128/AAC.04623-14.

204. Omoto, S. et al. Characterization of influenza virus variants induced by treatment with the endonuclease inhibitor baloxavir marboxil. Sci. Rep. (2018) doi:10.1038/s41598018-27890-4.

205. Xia, C. et al. PARP1 Enhances Influenza A Virus Propagation by Facilitating Degradation of Host Type I Interferon Receptor. J. Virol. (2020) doi:10.1128/jvi.01572-19.

206. Alfonso, R., Rodriguez, A., Rodriguez, P., Lutz, T. \& Nieto, A. CHD6, a Cellular Repressor of Influenza Virus Replication, Is Degraded in Human Alveolar Epithelial Cells and Mice Lungs during Infection. J. Virol. (2013) doi:10.1128/jvi.00554-12.

207. Su, W. C. et al. Pooled RNAi screen identifies ubiquitin ligase Itch as crucial for influenza A virus release from the endosome during virus entry. Proc. Natl. Acad. Sci. U. S. A. (2013) doi:10.1073/pnas.1312374110.

208. Su, W.-C., Hsu, S.-F., Lee, Y.-Y., Jeng, K.-S. \& Lai, M. M. C. A Nucleolar Protein, Ribosomal RNA Processing 1 Homolog B (RRP1B), Enhances the Recruitment of Cellular mRNA in Influenza Virus Transcription. J. Virol. (2015) doi:10.1128/jvi.01487-15.

209. Diot, C. et al. Influenza A Virus Polymerase Recruits the RNA Helicase DDX19 to Promote the Nuclear Export of Viral mRNAs. Sci. Rep. (2016) doi:10.1038/srep33763.

210. Jorba, N. et al. Analysis of the interaction of influenza virus polymerase complex with human cell factors. Proteomics (2008) doi:10.1002/pmic.200700508.

211. Thulasi Raman, S. N. et al. DDX3 Interacts with Influenza A Virus NS1 and NP Proteins and Exerts Antiviral Function through Regulation of Stress Granule Formation. J. Virol. (2016) doi:10.1128/jvi.03010-15. 
212. Park, E. et al. Co- degradation of interferon signaling factor DDX3 by PB1- F2 as a basis for high virulence of 1918 pandemic influenza. EMBO J. (2019) doi:10.15252/embj.201899475.

213. Momose, F. et al. Cellular Splicing Factor RAF-2p48/NPI-5/BAT1/UAP56 Interacts with the Influenza Virus Nucleoprotein and Enhances Viral RNA Synthesis. J. Virol. (2001) doi:10.1128/jvi.75.4.1899-1908.2001.

214. Tsai, P. L. et al. Cellular RNA Binding Proteins NS1-BP and hnRNP K Regulate Influenza A Virus RNA Splicing. PLoS Pathog. doi:10.1371/journal.ppat.1003460.

215. Yang, C. H. et al. Influenza A virus upregulates PRPF8 gene expression to increase virus production. Arch. Virol. (2017) doi:10.1007/s00705-016-3210-3.

216. Fournier, G. et al. Recruitment of RED-SMU1 Complex by Influenza A Virus RNA Polymerase to Control Ciral mRNA Splicing. PLoS Pathog. (2014) doi:10.1371/journal.ppat.1004164.

217. Ward, S. E. et al. Host modulators of H1N1 cytopathogenicity. PLoS One (2012) doi:10.1371/journal.pone.0039284.

218. Landeras-Bueno, S., Jorba, N., Pérez-Cidoncha, M. \& Ortín, J. The splicing factor proline-glutamine rich (SFPQ/PSF) is involved in influenza virus transcription. PLoS Pathog. (2011) doi:10.1371/journal.ppat.1002397.

219. Fang, A., Bi, Z., Ye, H. \& Yan, L. SRSF10 inhibits the polymerase activity and replication of avian influenza virus by regulating the alternative splicing of chicken ANP32A. Virus Res. (2020) doi:10.1016/j.virusres.2020.198063. 


\section{6) Acknowledgments}

This work was supported by ANR grant (ANR-18-CE11-0028) to NN and SC.

\section{7) Figure Captions}

\section{Figure 1: FluPol transcription and replication.}

(A) Incoming vRNPs are imported into the nucleus and used as templates for primary transcription. Viral mRNAs are exported from the nucleus and translated by the cellular translation machinery. Newly synthesised nucleoprotein and polymerase subunits are reimported into the nucleus, where the formation of progeny vRNPs occurs. Genome replication involves an unprimed mechanism, producing full-length positive strand cRNA (+), which is then replicated into progeny vRNA (-). Progeny vRNPs are substrates for secondary transcription and replication. (B) The FluPol transcription cycle starts with cap-snatching from nascent RNAP II derived 5' -capped RNAs by the association of the PB2 cap-binding domain to the capped moiety and cleavage by the PA endonuclease domain (a), followed by repositioning of the primer to the polymerase active site where viral mRNA synthesis is initiated (b). Elongation proceeds with the addition of NTPs to the 3 ' end of the capped primer (c), the template rebinds the polymerase on a secondary site (d), remaining in close proximity for the recycling of the polymerase. The released product has a 5' cap derived from the snatched host RNA and a poly(A) tail, produced by the polymerase through a stuttering mechanism (e).

Figure 2: The initiation, pausing and pause release steps of early RNAP II transcription.

(a) Initiation starts with the recruitment of GTFs to the promoter region, followed by recruitment of RNAP II and the Mediator complex, which binds to the unphosphorylated 
RNAP II CTD. TFIIH phosphorylates the CTD on Ser5 and thereby triggers promotor escape.

(b) The capping apparatus binds to the Ser5P CTD and the unphosphorylated DSIF CTR, leading to the synthesis of the cap structure on the 5' end of the nascent RNA (c) Promoterproximal pausing is associated with binding of RNAP II to the pausing factors DSIF and NELF. (d) Phosphorylation of DSIF, NELF and RNAP II CTD on Ser2 by CDK9, the kinase component of P-TEFb, leads to RNAP II pause release and recruitment of the elongation factors PAF1 and SPT6 resulting in an active elongating complex. The 5' cap structure is bound by the nuclear CBC.

\section{Figure 3: Enzymatic reactions of cap synthesis.}

Addition of each chemical group is highlighted with a different colour. The $\gamma$ phosphate is hydrolysed by the RNA-5'-triphosphatase (RT) (a) and guanylyl transfer is catalysed by the guanylyltransferase (GT) (b). In mammals, RT and GT activity reside in the capping enzyme (CE). Methylation of the $\mathrm{N}^{7}$ of the guanosine by RNMT (c) leads to the formation of the cap 0 structure. A series of methylations by CMTR1 (d) and CMTR2 (e) further modify the hydroxyl groups of the first and second nucleotide, respectively, leading to the cap 1 and cap 2 structures. Additional methylation on the $\mathrm{N}^{6}$ of the first adenine by CAPAM occurs in some capped RNAs (f).

\section{Figure 4: Modes of FluPol binding to the Ser5P CTD.}

Co-crystal structures of influenza A, B and C polymerases bound to CTD mimicking peptides. Left: Influenza A/little yellow-shouldered bat/2010/H17N10 (FluPol ${ }_{\mathrm{A}}$ ), PDB: 5M3H; middle: Influenza B/Memphis/13/03 polymerase $\left(\right.$ FluPol $\left._{\mathrm{B}}\right)$, PDB: 5M3J; right: Influenza C/Johannesburg/1/66 (FluPol ${ }_{\mathrm{c}}$ ), PDB: 6F5O. Polymerases are color-coded with PA $\left(\mathrm{P} 3\right.$ for $\mathrm{FluPol}_{\mathrm{c}}$ ) in green, $\mathrm{PB} 1$ in grey, $\mathrm{PB} 2$ in orange. The PA endonuclease and PB2 cap- 
binding domains are highlighted in darker shades of green and orange, respectively. The bound CTD peptides are shown in blue.

\section{Figure 5: Open questions on FluPol cap-snatching: timing and context.}

The precise nuclear localisation of FluPol transcription in the context of promoter and gene body condensates is unclear. Other unknowns include the precise timing of capsnatching with respect to cap-completion, CBC binding to the nascent capped RNA and phosphorylation of the transcription machinery by $\mathrm{P}-\mathrm{TEFb}$ resulting in pause release. Potential interactions with other viral factors or cellular factors involved in RNAP II transcription could be involved in coordinating cap-snatching in the context of cellular RNAP II transcription. 
Table 1. Influenza virus interplay with host factors involved in cellular mRNA biogenesis.

\begin{tabular}{|c|c|c|c|}
\hline Gene* & $\begin{array}{l}\text { Loss-of-function } \\
\text { screen }\end{array}$ & Interaction screen & Functional studies \\
\hline Basal RNAP II Tran & & & \\
\hline CCNT1/CDK9 & & & 131 \\
\hline CMTR1 & 122 & & 122 \\
\hline GTF2I & . & $\begin{array}{l}125 \\
146\end{array}$ & \\
\hline HTATSF1 (Tat-SF1) & $\begin{array}{l}142 \\
139\end{array}$ & 124 & 144 \\
\hline MED6 & $\begin{array}{l}140 \\
145\end{array}$ & & \\
\hline NCBP1 & & $\begin{array}{l}125 \\
137\end{array}$ & 199 \\
\hline NCBP2 & 122 & 137 & \\
\hline NCPB3 & $\begin{array}{l}145 \\
137\end{array}$ & & \\
\hline PARP1 & 142 & 129 & $\begin{array}{l}143 \\
205\end{array}$ \\
\hline POLR2A (RPB1) & & $\begin{array}{l}125 \\
124 \\
130\end{array}$ & 28 \\
\hline POLR2B (RPB2) & & $\begin{array}{l}126 \\
146 \\
125 \\
130\end{array}$ & \\
\hline SUPT5H (SPT5) & & $\begin{array}{l}126 \\
125 \\
124\end{array}$ & \\
\hline SUPT6H (SPT6) & $\begin{array}{l}140 \\
141\end{array}$ & 125 & \\
\hline TRIM28 & 134 & 126 & 138 \\
\hline
\end{tabular}




\begin{tabular}{|c|c|c|}
\hline CHD1 & & 149 \\
\hline CHD6 & 130 & 148 \\
\hline
\end{tabular}

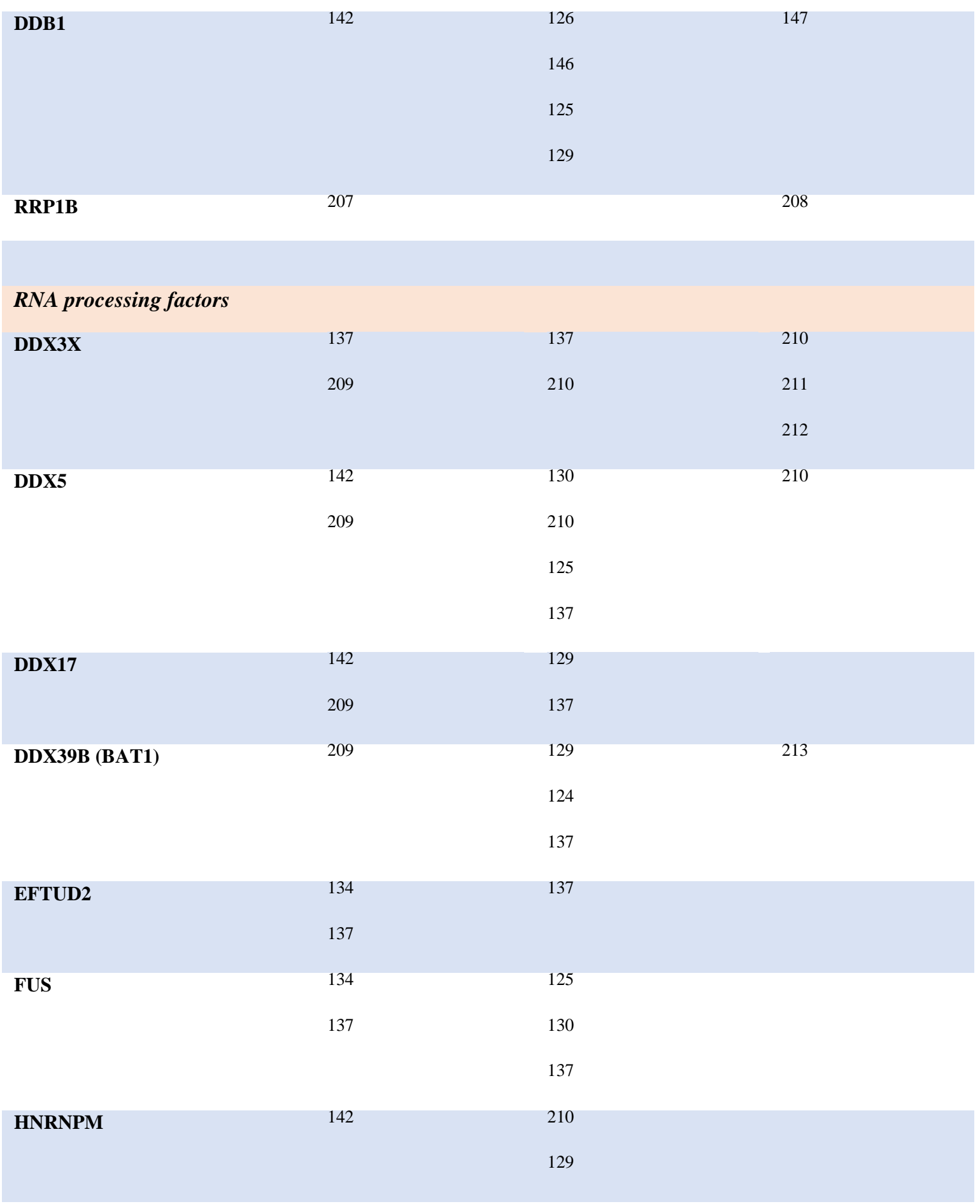




$\begin{array}{lccc}\text { NUDT21 (CPSF5) } & 122 & 137 & 215 \\ \text { PRPF8 } & 134 & 124 & \\ & 137 & 125 \\ & 140 & 137\end{array}$

$\begin{array}{lcc}\text { RED-SMU1 } & & 216 \\ \text { SART3 } & 122 & 125 \\ & & 137\end{array}$

\begin{tabular}{|c|c|c|c|}
\hline SF3A1 & $\begin{array}{l}140 \\
135\end{array}$ & & \\
\hline SF3B1 & $\begin{array}{l}134 \\
137 \\
140\end{array}$ & 137 & \\
\hline SF3B2 & $\begin{array}{l}134 \\
137\end{array}$ & $\begin{array}{l}125 \\
137\end{array}$ & \\
\hline SF3B3 & $\begin{array}{l}134 \\
137\end{array}$ & 137 & \\
\hline SFPQ & $\begin{array}{l}122 \\
217 \\
142\end{array}$ & $\begin{array}{l}210 \\
137\end{array}$ & $\begin{array}{l}218 \\
210\end{array}$ \\
\hline SNRNP70 & $\begin{array}{l}140 \\
135\end{array}$ & 125 & \\
\hline SNRPB & $\begin{array}{l}134 \\
137\end{array}$ & 137 & \\
\hline SNRPD3 & $\begin{array}{l}134 \\
137\end{array}$ & 137 & \\
\hline SRSF10 & & $\begin{array}{l}126 \\
125\end{array}$ & 219 \\
\hline
\end{tabular}

* Genes for which an interplay with influenza virus was documented in at least two independent high-throughput screens and/or in at least one dedicated functional study. 


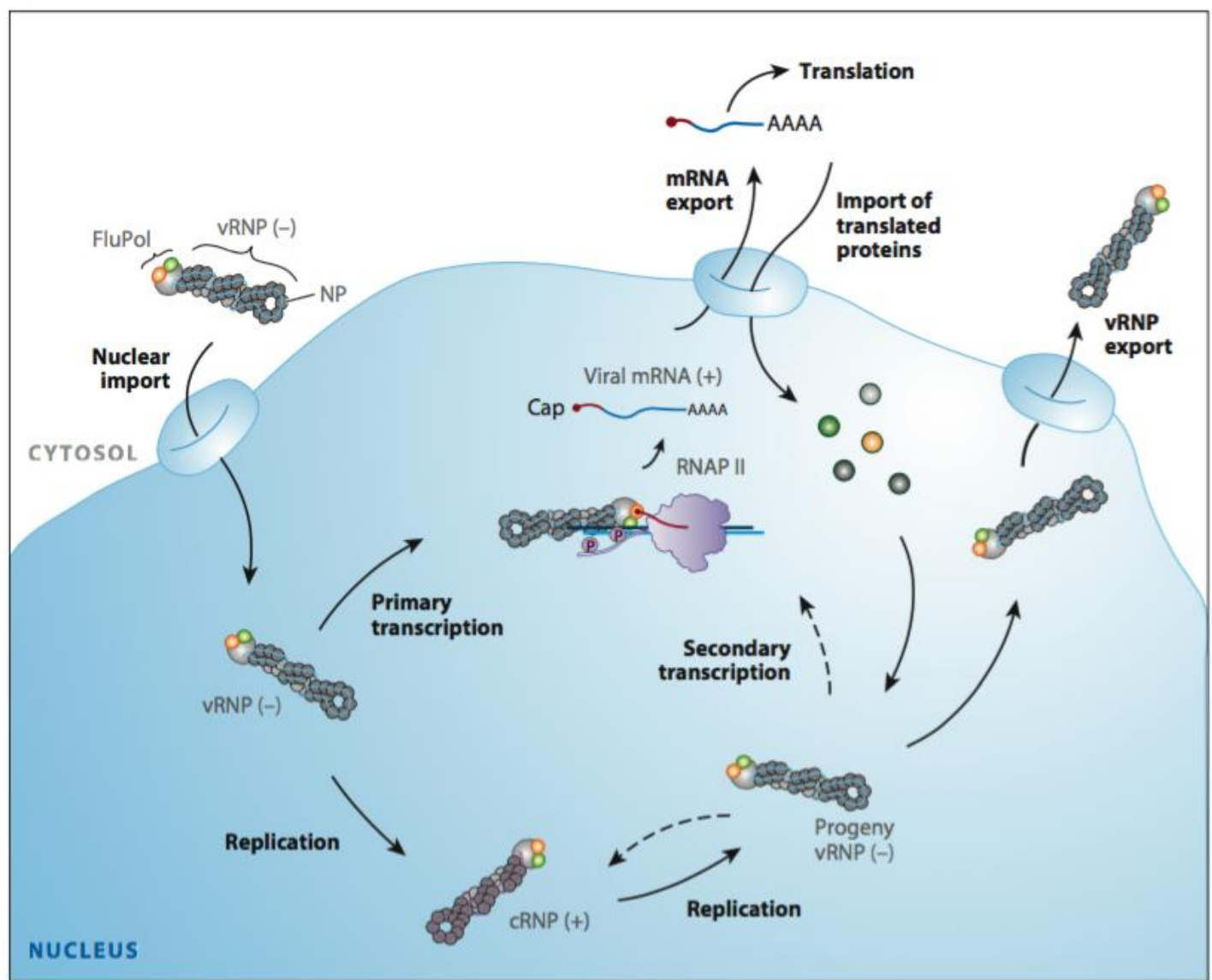

b

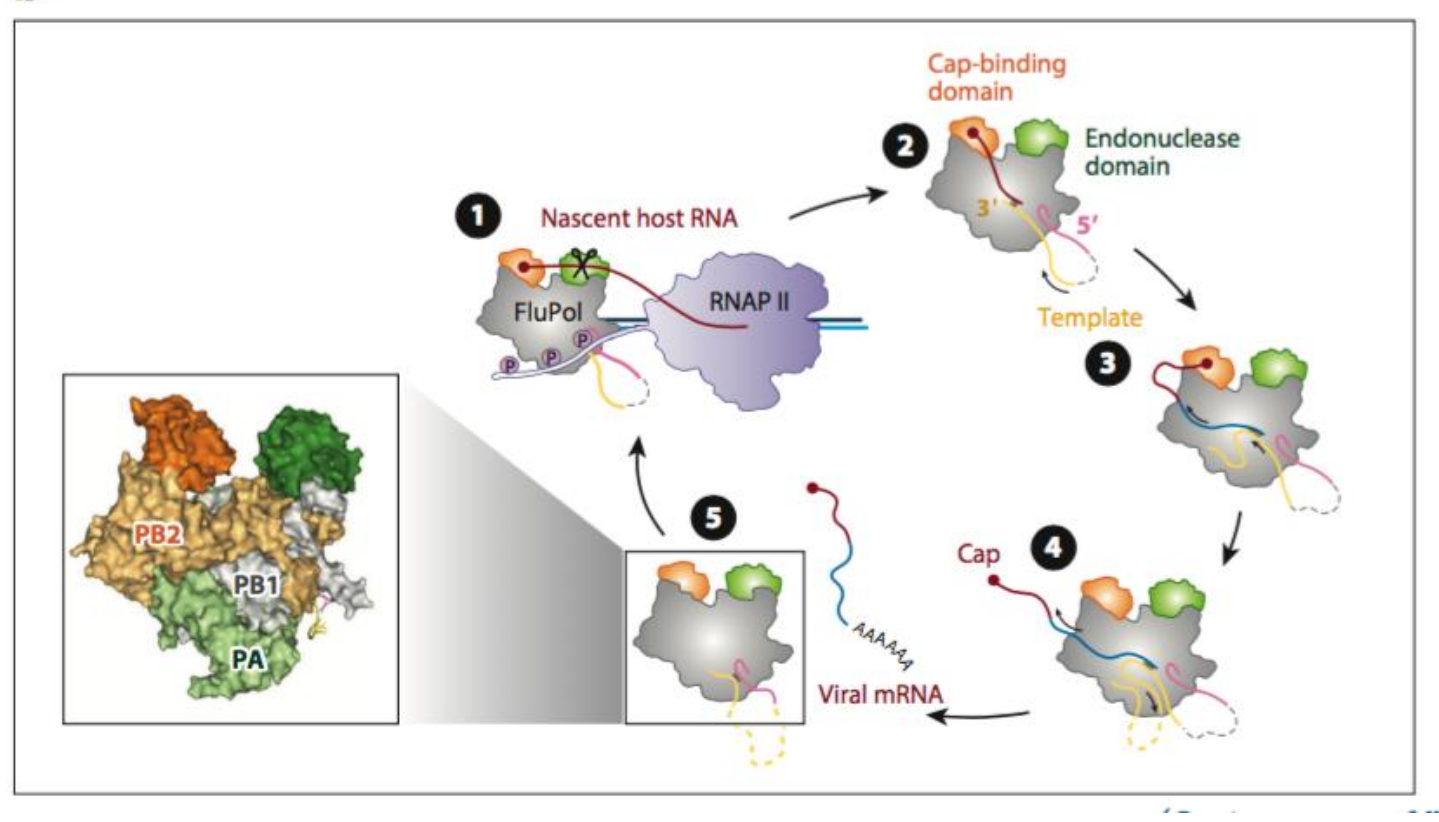

Figure 1 




Figure 2 


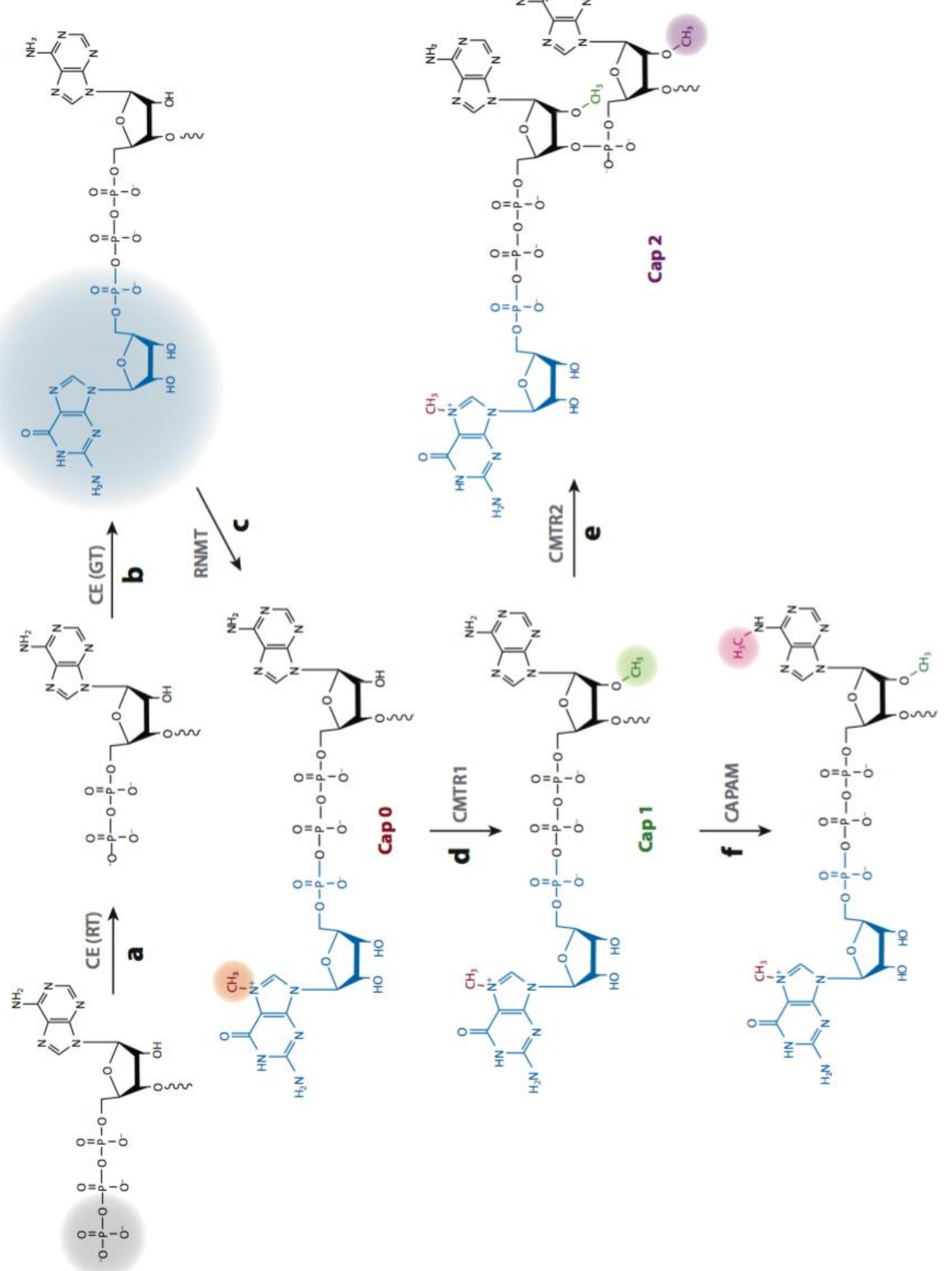

Figure 3 
a FluPolA

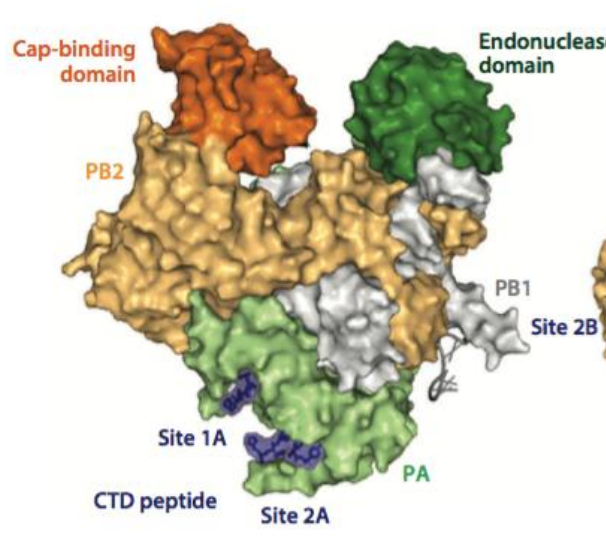

b FluPols

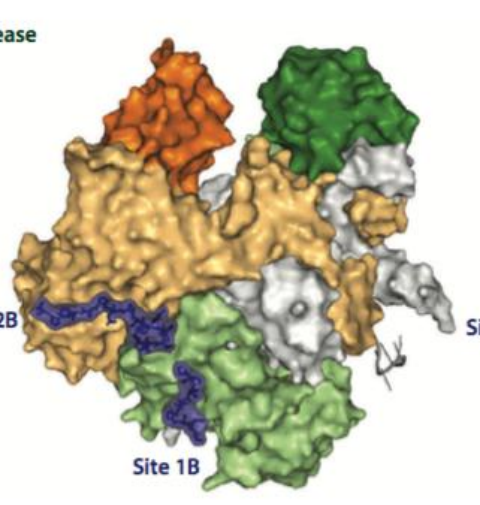

C FluPolc



Figure 4 


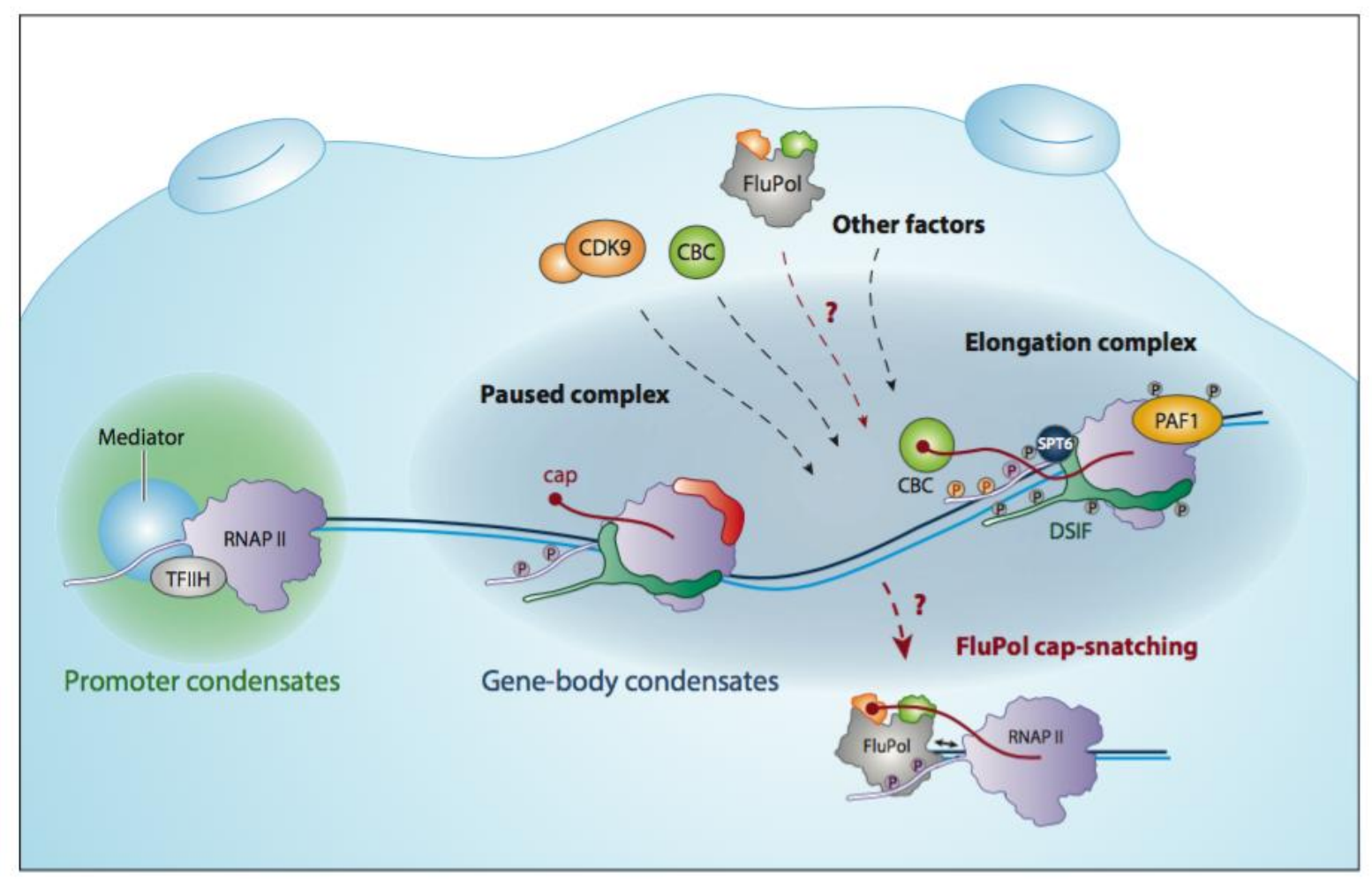

Figure 5 